\title{
Evolutionary Hypotheses for Human Childhood
}

\author{
BARRY BOGIN \\ Department of Behavioral Sciences, University of Michigan-Dearborn, \\ Dearborn, Michigan 48128 \\ KEY WORDS childhood; heterochrony; neoteny; insertion model
}

\begin{abstract}
The origins of human childhood have fascinated scholars from many disciplines. Some researchers argue that childhood, and many other human characteristics, evolved by heterochrony, an evolutionary process that alters the timing of growth stages from ancestors to their descendants. Other scholars argueagainst heterochrony, but so far have not offered a well-devel oped alternative hypothesis. This essay presents such an alternative. Childhood is defined as a unique developmental stage of humans. Childhood is the period foll owing infancy, when the youngster is weaned from nursing but still depends on older people for feeding and protection. The biological constraints of childhood, which include an immature dentition, a small digestive system, and a cal orie-demanding brain that is both relatively large and growing rapidly, necessitate the care and feeding that older individuals must provide. Evidence is presented that childhood evolved as a new stage hominid life history, first appearing, perhaps, during the time of Homo habilis. The value of childhood is often ascribed to learning many aspects of human culture. It is certainly true that childhood provides "extra" time for brain development and learning. However, the initial selective value of childhood may be more closely related to parental strategies to increase reproductive success. Childhood all ows a woman to give birth to new offspring and provide care for existing dependent young. Understanding the nature of childhood helps to explain why humans have lengthy development and low fertility, but greater reproductive success than any other species. Yrbk Phys Anthropol 40:63-89, 1997. @ 1997 Wiley-Liss, Inc.
\end{abstract}

Behold the Child among his newborn blisses, A six-years' Darling of a Pygmy size!

See, where 'mid work of his own hand helies, Fretted by sallies of his mother's kisses, With light upon him from his father's eye

-W. Wordsworth: Intimations of I mmortality (1802-1804)

Childhood fascinates scholars and practitioners from many disciplines. Virtually all human cultures recognize a time of life that may be called "childhood." Many historical sources from Egyptian times to the 19th century, including Wordsworth in the poem above, mention that "childhood" occupies the first 6 to 7 years of life (Boyd, 1980). Some explanations for the origins and functions of childhood have been proposed, but none of these is accepted universally. Perhaps the lack of agreement is due to the nature of human evolutionary biology. Allison J olly, author of TheE volution of PrimateBehavior, states that "human evolution is a paradox. We have become larger, with long life and immaturity, and few, much loved offspring, and yet we are more, not less adaptable." In an attempt to resolve the paradox of human evolution and our peculiar life history J olly 


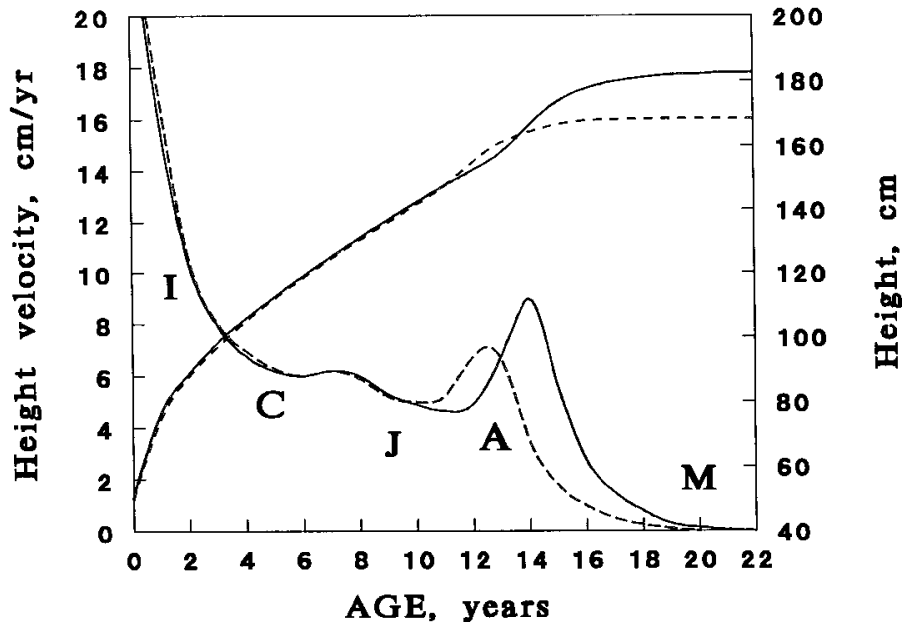

Fig. 1. I dealized mean velocity and distance curves of growth in height for healthy girls (dashed lines) and boys (solid lines) showing the postnatal stages of the pattern of human growth. Note the spurts in growth rate at mid-childhood and adol escence for both girls and boys. The stages of postnatal are abbreviated as follows: I, infancy; C, childhood; J , juvenility; A, adolescence; M , matureadult. Data used to construct the curves come from Prader (1984) and Bock and Thissen (1980). concludes in the next sentence that "mental agility buffers environmental change and has replaced reproductive agility" (1985, p. 44). The reference to reproductive agility means that we are a reproductively frugal species compared with those that lavish dozens, hundreds, or thousands of offspring on each brood or litter. However, a paradox remains, for the emphasis on "brain power" rather than reproduction is an apparent exception to Darwin's rules of natural selection. Evolutionary success is traditionally measured in terms of the number of offspring that survive and reproduce. Biological and behavioral traits do not evolve unless they confer upon their owners some degree of reproductive advantage in terms of survivors a generation or more later. If we are truly interested in our immortality, or at least that of our DNA, then why do we not produce more offspring, instead of a few mentally agile offspring?

Another question is, why do our offspring take so long to reach reproductive age? After all, our genetic immortality requires that we have grandchildren, great-grandchildren, and so on. Yet we take two decades of postnatal development to reach reproductively successful adulthood. Moreover, our path from birth to maturity is sinuous, meandering through alternating periods of rapid and relatively slow development. This may be seen in the examples of the distance and velocity curves of growth for healthy boys and girls illustrated in Figure 1. Why do our offspring not take a more direct and rapid path to maturity?

This essay attempts to answers these questions and paradoxes in terms of the evolution of human growth and development. Throughout the essay the focus is on children and childhood. It is argued here that childhood is a unique stage of the human life cycle, a stage not to be found in the life cycle of any other living mammal. It is important to define clearly what is meant by childhood, for often the terms "child," "juvenile," and "adolescent" are used interchangeably in the literature.

Childhood is defined here as the period following infancy, when the youngster is weaned from nursing but still depends on older people for feeding and protection. Infants by definition are exclusively or partially breast-fed. One survey of the worldwide variation in the age for termination of breast-feeding, that is weaning age, finds it to occur at a median age of 36 months after birth (Dettwyler, 1995). Though no longer breast-fed, children are still dependent on older people for feeding. Several biological and behavioral characteristics of the youngster necessitate this dependency of childhood. In terms of feeding there are three major biological factors (Fig. 2): 1) children continue the rapid brain growth experienced by infants and need a diet dense in energy and protein to support this brain growth, 2) children possess deciduous teeth, with thin enamel and shallow roots, and cannot pro- 
Fig. 2. Growth curves for different body tissues. The "brain" curve is for total weight of the brain (Cabana et al., 1993). The "dentition" curve is the median maturity score for girls based on the seven left mandibular teeth $(11,12, \mathrm{C}, \mathrm{PM} 1, \mathrm{PM}$, M1, M2) using thereference data of Demirjian (1978). The "body" curve represents growth in stature or total body weight. The "reproductive" curve represents the weight of the gonads and primary reproductive organs (Scammon, 1930).

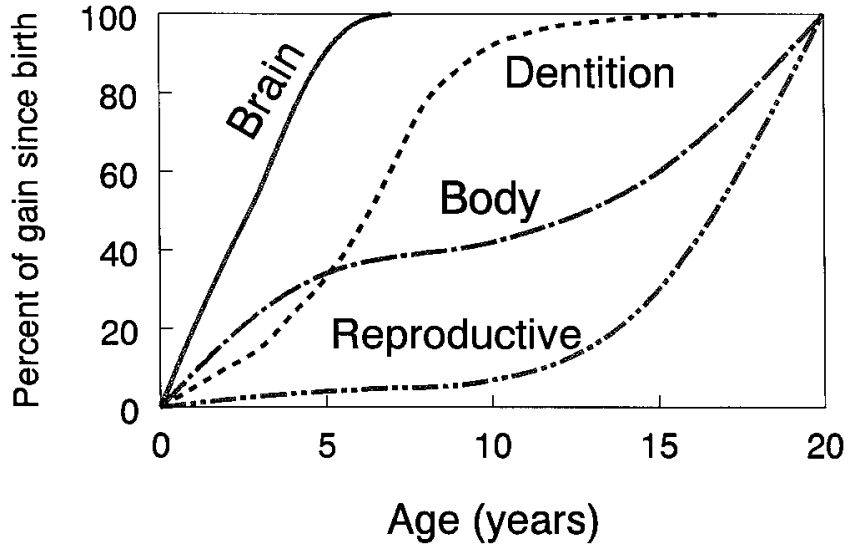

cess the adult-type diet, and 3) children have relatively small body size, and hence a small digestive system, which limits total food intake, furthering the requirement for nutrient-densefoods. These physical characteristics are coupled with motor and cognitive immaturity, as well as social inexperience. All of these factors render the child dependent on ol der individuals for care.

The childhood stage precedes the juvenile stage of the life cycle. A juvenile stage is common to most species of social mammals (Pereira and Fairbanks, 1993), and is a time of feeding independence from ol der individuals prior to the onset of reproductive maturity (Pereiera and Altmann, 1985). Based on a variety of biological, behavioral, and cognitive traits and abilities that are described in detail below, human children enter the juvenile stage at about 7 years of age. By these criteria, the human childhood stage of life spans the time from about 3 to 7 years of age (Bogin, 1990, 1995; Bogin and Smith, 1996).

More detailed evidence for this biological definition of childhood is presented later in this essay. One point to stress at this juncture, however, is that childhood is likely to be a new life cycle stage, that was evol ved de novo into hominid life history. This view of childhood stands in diametrical opposition to older, but still widely held views that childhood evolved by altering the developmental timing of the preexisting life stages of our primate ancestors. The two most popular hypotheses in this regard invoke either neoteny or hypermorphosis as the primary agent of human evolution. Neoteny may be thought of as a slowing down of the rate of development. Neoteny produces an adult descendant that retains many immature characteristics of its ancestor. Hypermorphosis may be defined, at this point, as an extension of the growth and development period of the descendant beyond that of the ancestor. Hypermorphosis produces a descendant with features that are hypermature compared with the ancestor. This essay will show that both the Peter Pan scenario of neoteny and the Methuselah-like development of hypermorphosis are inadequate to account for the evolution of childhood. M oreover, neither neoteny nor hypermorphosis can unravel the paradox of human evolution. To resolve the puzzle of why we have so few offspring, why they take so long to devel op and reproduce, and why our rate of growth takes a serpentine path to adulthood requires a new, and more mature, view of childhood and its place in human evolution.

\section{HUMAN ONTOGENY AND HETEROCHRONY}

Ontogeny refers to the process of growth, development, and maturation of the individual organism from conception to death. It is virtually axiomatic that every species has its own unique pattern of ontogeny (Bonner, 1965; Gould, 1977). During hominid evolution the form and function of our ancestor's structural and regulatory DNA was reworked to produce the genetic basis for the ontogeny of the human species. The literature is replete with proposals for how the reworking occurred. One tradition in the 
study of human evolution looks for a single major cause or process. It has been argued that humans evolved when we became bigbrained apes, terrestrial apes, killer apes, hunting apes, aquatic apes, tool making apes, symbolic apes, monogamous apes, foodsharing apes, and, even, apes with ventralventral copulatory behavior. None of these, or any other single-factor hypothesis, proves to be helpful to understand human evolution, for a non-human primate exception can always be found. Another tradition looks instead at the pattern of ontogeny. In the book Size and Cycle, J.T. Bonner (1965) devel ops the idea that the stages of the life cycle of an individual organism, a colony, or a society are "the basic unit of natural selection." Bonner's focus on life cycle stages follows from the research of several 19thand 20th-century embryologists who proposed that speciation is often achieved by altering rates of growth of existing life stages and by adding or deleting stages.

A history of research on life cycle evolution was published by S.J. Gould in the book Ontogeny and Phyl ogeny (1977). Gould handily summarizes the mechanisms for biological change over time by stating, "Evolution occurs when ontogeny is altered in one of two ways: when new characters are introduced at any stage of development with varying effects upon subsequent stages, or when characters already present undergo changes in devel opmental timing. Together, these two processes exhaust the formal content of phyletic change." Gould contends that it is the second process that accounts for human evolution. This process is called heterochrony. Quoting Gould again, "this book is primarily a long argument for the evolutionary importance of heterochronychanges in the relative time of appearance and rate of development for characters already present in ancestors" (author's italics). Gould explains that there are several types of heterochronic processes, but only one accounts for human evolution. This is neoteny, defined in the glossary of Gould's book as "paedomorphosis (retention of formally juvenile characters by adult descendants) produced by retardation of somatic development." In a subsequent publication Gould provides a somewhat more readable definition: "I n neoteny rates of development slow down and juvenile stages of ancestors become adult features of descendants. Many central features of our anatomy link us with the fetal and juvenile stages of [non-human] primates..." (Gould, 1981, p. 333).

\section{NEOTENY AND HUMAN EVOLUTION}

That humans of all ages are essentially child-like in morphology, behavior, and cognitive potential is the essence of the concept of neoteny. Notions of human neoteny may be traced back as far as biblical writings (Montagu, 1989), and the concept has dominated popular and scientific attitudes toward the evolution of human growth for hundreds of years. William Wordsworth, for example, praised the concept of neoteny in 1802 with words of innocence and hope:

$$
\begin{gathered}
\text { My heart leaps up when I behold } \\
\text { A rainbow in the sky: } \\
\text { So was it when my life began; } \\
\text { So is it now I am a man; } \\
\text { So be it when I shall grow old, } \\
\text { Or let me die! } \\
\text { The child is father of the man; } \\
\text { And I could wish my days to be } \\
\text { Bound each to each by natural piety. }
\end{gathered}
$$

The term "neoteny" was coined by J ulius Kollman in 1885 to describe the sexual maturation of the axol otl, a urodel e amphibian (salamander), while still in its aquatic, gill breathing stage of development. Ashley Montagu (1989) states that Kollman intended neoteny to mean "retaining youth" but that Kollman confused the Greek word teinein (to stretch) with the Latin word tenere (to retain). Figure 3 presents contemporary dictionary definitions, as well as another current medical usage of the Latin root of the term. Despite the scatological humor that may be found in Kollman's etymological error, Montagu and Gould believe that Kollman had the right idea, that is, neoteny is the process for human evolution.

The idea that neoteny is the primary process for humanization was first formalized scientifically by Louis Bolk in 1926 (see Montagu, 1989, for a concise review of historical sources). Gould acknowledges that much of Bolk's neoteny is really an argument for scientific racism and sexism. Nevertheless, Gould tries to retain the baby of neoteny while discarding the bath water of 


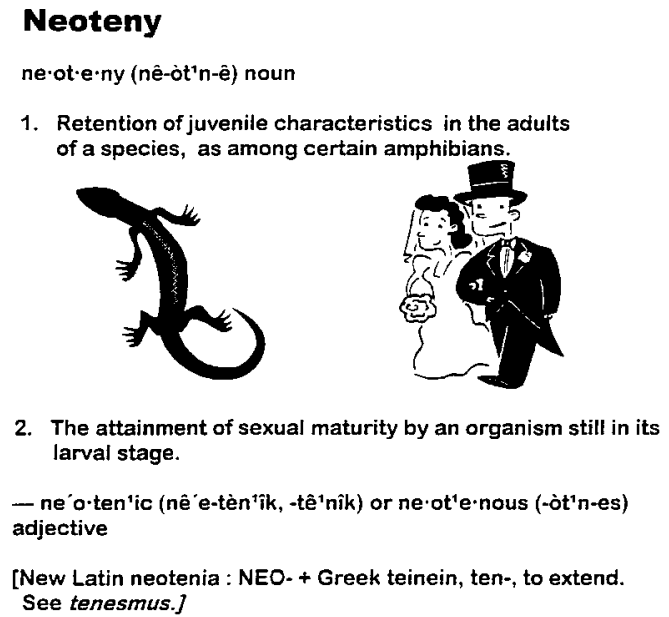

2. The attainment of sexual maturity by an organism still in its larval stage.

- ne'o'ten'ic (nê'e-tèn'îk, -têt'nîk) or ne'ot'e'nous (-òt' n-es) adjective

[New Latin neotenia : NEO + Greek teinein, ten-, to extend. See tenesmus.]

te'nes'mus (te-nèz'mes) noun

A painfully urgent but ineffectual attempt to urinate or defecate.

[Medieval Latin tênesmus, variant of Latin tênesmos, from Greek teinesmos, from teinein, to strain, stretch.]

Fig. 3. Definitions and etymology of the term "neoteny."

racist and sexist science. To do so, Gould suggests that the major difference between human and non-human primate growth is that humans mature sexually while still in an infantile or juvenile stage of physical devel opment.

Gould expressed his ideas on heterochrony via neoteny in terms of a "clock model." The clock has two hands, one that calibrates a size arc and the other that measures a shape arc. The clock sits above a type of bar-shaped calendar that records time in the form of biological age, that is, age at sexual maturation. The clock may be used to compare an ancestor with its descendants. The ancestor's clock is fixed with the two hands at the zenith of the arcs and age of sexual maturation at the mid-point of the calendar. The descendant's clock measures changes in size, shape, and age at maturation by differences in these three vectors. The major point that Gould emphasizes with the clock model is that size, shape, and maturation are di sassociable from each other and can evolve independently. Figure $4 a$ is Gould's clock for human evolution via neoteny. Humans have larger size (body, brain, etc.) and mature at a later age, compared with our ancestor, but retain the shape of an immature ancestor.

Gould makes very clear his interpretation of the consequences of neoteny. "If humans evolved, as I believe, by neoteny, . . . then we are, in a more than metaphorical sense, permanent children" (1981, p. 333). Could it be truethat we "permanent children"? Some eminent scholars believeit. Benjamin F ranklin wrote, "Our whole life is but a greater and longer childhood." Sigmund Freud was more circumspect: "In our innermost soul we arechildren and remain so for the rest of our lives." Montagu is the most emphatic: "We are intended to remain in many ways childlike, we were never intended to grow up into the kinds of adults we have become. ... Our uniqueness lies in always remaining in a state of development" (all quotes from Montagu, 1989).

Given the scientific respectability of works on neoteny by Gould and Montagu, the term and the concept have been popularized in western society and adopted into many other arenas. The following are some recent examples. Philosophers posit neoteny as the process leading to the human capacity for language (Goldsmith, 1993; Brown, 1995). Psychiatrists al lege it is the reason humans are so playful (Brown, 1995). Some types of neurological dementia are described as "a failure of neoteny" (Bemprad, 1991). Human female sexual attractiveness is clai med to be a function of neoteny (J ones, 1995). Taking this cue, the advertising industry employs human infants, children, and neotenous adult women to sell all sorts of products. Moreover, the product designers make the inanimate objects (everything from tea pots to automobiles) more appeal ing and purchasable by making them seem neotenous, that is, shaped like a human infant or child (Boym, 1994, and see Box 1). Finally, a prominent social anthropologist claims that human evolution via neoteny allows for the development of human culture, especially religion (La Barre, 1991)!

\section{HYPERMORPHOSIS AND HUMAN EVOLUTION}

Despite the intellectual weight that biology (Gould), social philosophy (Franklin), psychoanalysis (F reud), anthropology (Montagu), and advertising bring to this issue, 

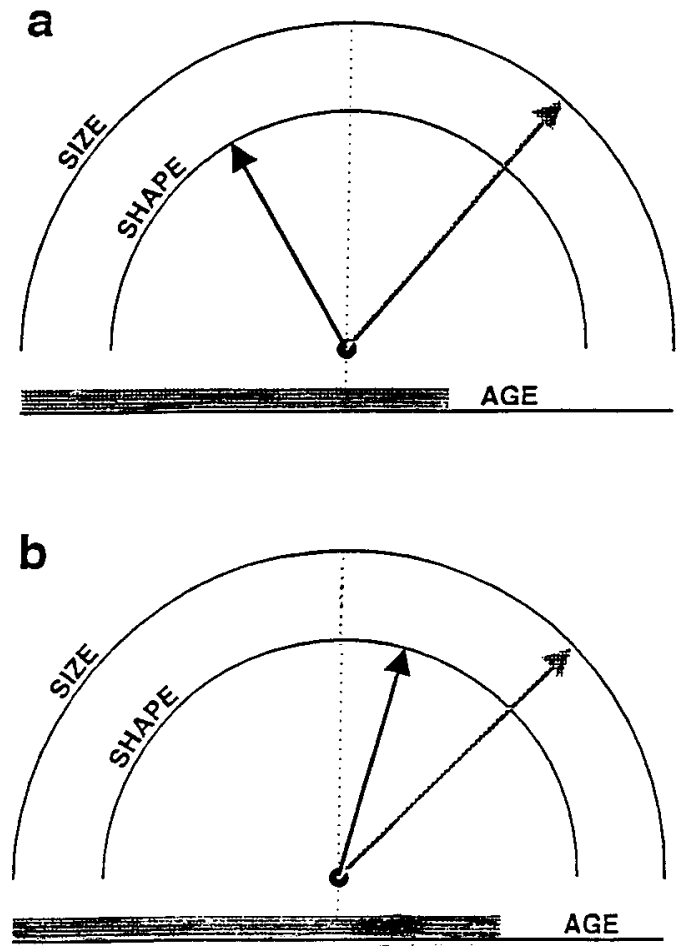

Fig. 4. a: Clock model for human evolution by neoteny. b: Clock model for human evolution by hypermorphosis. Adapted from Godfrey and Sutherland (1996), with permission.

and despite the popularity of neoteny as a cause célèbre for so many human traits and behaviors, the proposition that adult humans are permanent children is not accepted by all scholars. Michael McKinney and Kenneth McNamara (1991), in their book Heterochrony: The Evolution of Ontogeny, provide a detailed case against neoteny in human evolution. McKinney and $\mathrm{McNa}$ mara argue instead for another type of heterochronic process to account for human growth and evolution, namely hypermorphosis. They state their position as follows: "Neoteny is the process of growing slower. Yet humans do not grow particularly slow (relative to either chimp or our ancestors. .). What we do is delay the offset of virtually all developmental events (growth phases) so that each phase is longer. This is hypermorphosis" (p. xi). Figure 4b illustrates evolution by hypermorphosis using Gould's clock model. Compared with the neoteny cl ock, the hypermor phosis clock posits that humans have larger size, later maturation, and a more "mature" shape than our putative ancestor. Although McKinney and McNamara do admit that there are a number of non-hypermorphic features of humans "hypermorphosis seems to best explain most of those traits that make us human: large body size, large brain, long learning stage and life span" (p. xi).

According to heterochrony, humans are not permanent children; rather we are developmentally delayed and/or growth-prolonged apes. Adol ph Schultz (1960) proposed exactly this more than three decades ago. Figure 5 is his classic illustration of the progressive delay in the onset and offset of primate life stages. Hypermorphosis, therefore, is hardly a new idea, but is it the right idea?

Sue Taylor Parker (1996) thinks that hypermorphosis is the right idea, and she uses it to account for the evolution of human cognitive capacities. Parker applies Piaget's stage theory (Piaget and Inhelder, 1969) to analyze the cognitive devel opment of human and non-human primates. She finds that all primates share the first one or two stages (sensorimotor and preoperational). Only the human species progresses to the higher Piagetian stages (concrete operational and formal operations). Parker explains that the uniquely human stages were added by hypermorphosis, that is, by extending the period of cognitive development past that of the monkeys and apes. This negates neoteny, which in Parker's view would mean that human cognitive capacities evolved by halting mental development at early or intermediate stage of non-human primate development. To quote Parker, "Cognitively, humans are overdeveloped rather than underdeveloped apes" (p. 377).

Elizabeth Vrba (1996) agrees that hypermorphosis is the key process in human evolution, but she adds a twist to McKinney and McNamara's argument. Vrba's model of human evolution is set in the more general context of mammalian evolution in Africa. Vrba tries to show that climate change, specifically global cooling after 2.9 million years ago, resulted in an enlargement of 


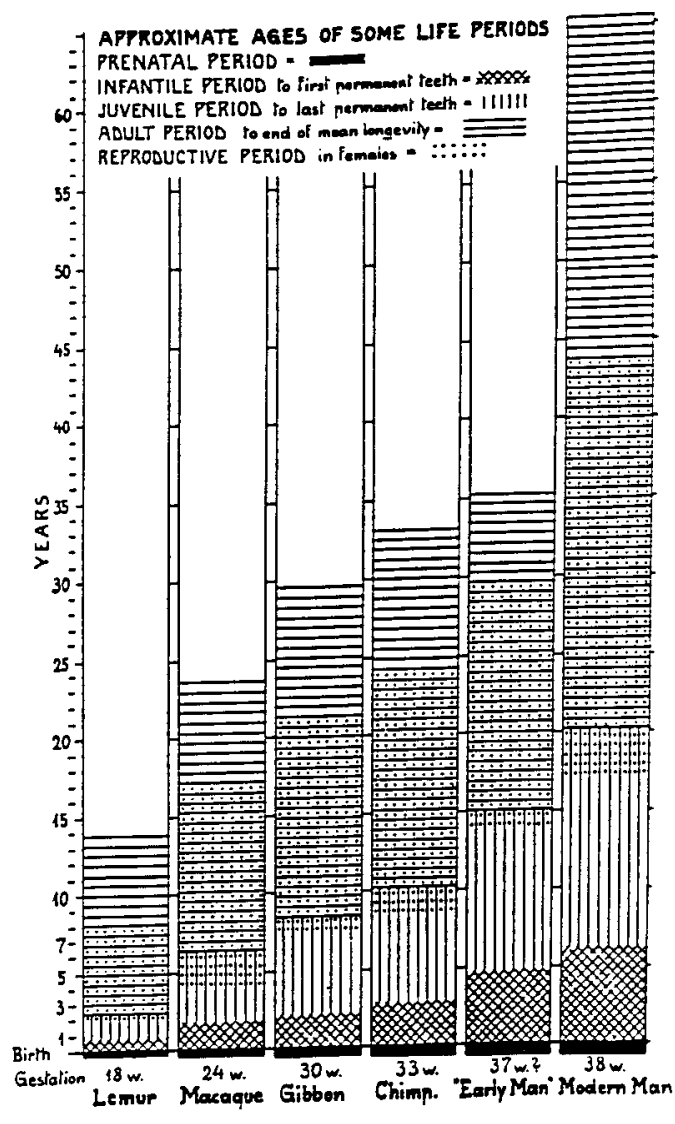

Fig. 5. Schultz's diagram of the proportional increase in the length of life stages across the scala naturae of living primates. Note that Schultz did not recognize the childhood stage for humans. Indeed, all species have the same life stages, which just increase in length from prosimian to human. The estimates for total length of life are based on average expectations rather than theoretical maximums. The data for "Early Man" are entirely speculative as no species is given and very little data were available when Schultz prepared this figure. Adapted from Schultz (1960) and Smith et al. (1994).

body size along with a relative decrease in limb length for several species of African mammals. Such morphological change in response to a cooler climate accords with Bergmann's and Allen's rules. According to Vrba, the African hominids alive at that time also conform to these rules, but the hominids are notable for a concurrent increase in brain size relative to body size. The general mammalian and the specifically hominid morphological change is explained to result from "the same evol utionary event of growth prolongation, or time hypermorphosis, as it acts on characters with different ancestral growth profiles in the same body plan." Vrba continues by stating that this "can result in a major reorganization-or 'shuffling'-of body proportions such that some characters become larger and others smaller, some hyperadult and others more juvenilized" (1996, p. 1). Many of the "ancestral growth profiles" of the hominids are, according to Vrba, still to be found in the great apes. She states, "I do not imply that the chimpanzee itself is ancestral, but only that its growth profile resembles that of the common ancestor" (1996, p. 17). Vrba predicts that by maintaining chimpanzee growth rates for legs, arms, torso, skull, brain, etc., and prolonging the total time for growth it is possible to derive a modern human morphology from an African pongid morphology.

\section{CRITIQUES OF NEOTENY AND HYPERMORPHOSIS}

The concepts of neoteny and hypermorphosis posit that modern humans evolved by either a delay or an extension of ancestral patterns of growth. Human anatomy, physiology, and behavior, however, cannot be explained by either of these simple processes. Criticisms of the application of neoteny to human evolution are not new. Kummer (1953), Bertalanffy (1960), and Starck and Kummer (1962) argued against neoteny, or what they called fetalization, on the basis of human crani ofacial and postcranial growth: “. . . the concept of 'fetalization' is to be refused with respect to the ontogeny and evolution of the human ... for this is not the result of an arrest of growth at an early phase but of a differentiation in changed direction. ... . Hence we may speak of 'retardation' but not of fetalization in human development" (Bertalanffy, 1960, p. 250). The phrase to emphasize in this quote is "differentiation in changed direction."

One specific example of the failure of neoteny and hypermorphosis to account for the direction of human development is the ontogeny of cranial growth related to language development. The human newborn cannot produce the speech sounds (phonemes) used by adult speakers of any lan- 
guage. Lieberman et al. (1972) and Laitman and Hei mbuch (1982) believe that the shape of the basicranium is the reason for this. They argue that newborns possess a basicranium with a relatively large angle of flexion (the angle formed by the junction of the occipital and vomer bones). This angle influences the shape of the soft tissues of the vocal track, especially the pharynx, and determines the nature of the vocal sounds the newborn can produce. During growth the angle of flexion becomes more acute, as the skull assumes child, juvenile, adolescent, and, finally, adult proportions. As this growth process takes place a greater range of linguistically recognizable phonemes is produced. In this one aspect of growth of the skull and its functional correlates neither neoteny nor hypermorphosis is a useful concept. Non-human primates never possess the human type of basicranial anatomy at any stage of their development, nor would they devel op this anatomy if they prolonged any of their stages of growth. As a consequence, non-human primates cannot produce human-like phoneme sounds.

A graphic case against neoteny and hypermorphosis can be made by considering the ontogeny of human body proportions. From fetus, to child, and to adult, human body proportions are so much altered that the mature morphology cannot be simply predicted from earlier stages of growth. Allometry, differential rates of growth of parts of the body relative to that of the body as a whole (Huxley, 1932), is the rule in primate, including human, development. Both positive and negativeall ometry take place in the ontogeny of human development (e.g., leg vs. trunk growth, or head vs. body growth). These allometric changes bring about functional differences between the adult and child in physical appearance and performance.

Brian Shea (1989) published the most cogent allometric analysis to date that rejects both neoteny or hypermorphosis as a "grand unification theory" for all of human growth and evolution. Shea is not antineoteny or anti-hypermorphosis per se, and in fact he allows that the human brain and cranium may have evolved by neoteny. But he argues that the human face, jaws, and the rest of the body did not evolve by neoteny. In Shea's view, a variety of heterochronic processes are responsible for human evol ution. The others may be hypermorphosis, acceleration (defined as an increase in the rate of growth or development), and hypomorphosis (defined as a delay in growth with no delay in the age at maturation). In Figure 6 are illustrated Shea's estimates for body size and shape as a consequence of neoteny and two types of hypermorphosis. None of these acting as a single process can produce the human adult size and shape from the human infant size and shape. The same holds true for acceleration and hypomorphosis. In agreement with Schultz, Shea states that "we [humans] have extended all of our life history periods, not merely the embryonic or juvenile ones" (pp. 84-5). Humans have al so altered rates of growth from those found in other primates and possible ancestors. To accomplish all this required, in Shea's view, several genetic changes or adjustments during human evolution. Since the hormones that regulate growth and development are, virtually, direct products of DNA activity, Shea proposes that the best place to look for evidence of the evolution of ontogeny is in the action of the endocrine system. According to Shea and others (e.g. Bogin, 1988) differences in endocrine action between humans and other primates negate neoteny or hypermorphosis as unitary processes and instead argue for a multiprocess model for human evolution.

In the male chimpanzee, for example, the concentration of testosterone in blood serum prior to puberty (from 1 to 6 years of age) averages 13 ng/dl (Martin et al., 1977). For the human male, the prepubertal serum testosterone concentration (from ages 1 to 12 years) averages 9 ng/dl (Winter, 1978). The peak velocity in long bone growth of eight male chimpanzees studied by Watts and Gavan (1982) occurred at a mean age of 10.96 years, with a standard deviation of 1.31 years. At this age, serum testosterone averages about $400 \mathrm{ng} / \mathrm{dl}$ (Martin et al., 1977). Peak height velocity in human boys from western Europe occurs at a mean age of 14.06 years, with a standard deviation of 0.92 years (Marshall, 1978), when serum testosterone levels average about $340 \mathrm{ng} / \mathrm{dl}$ 

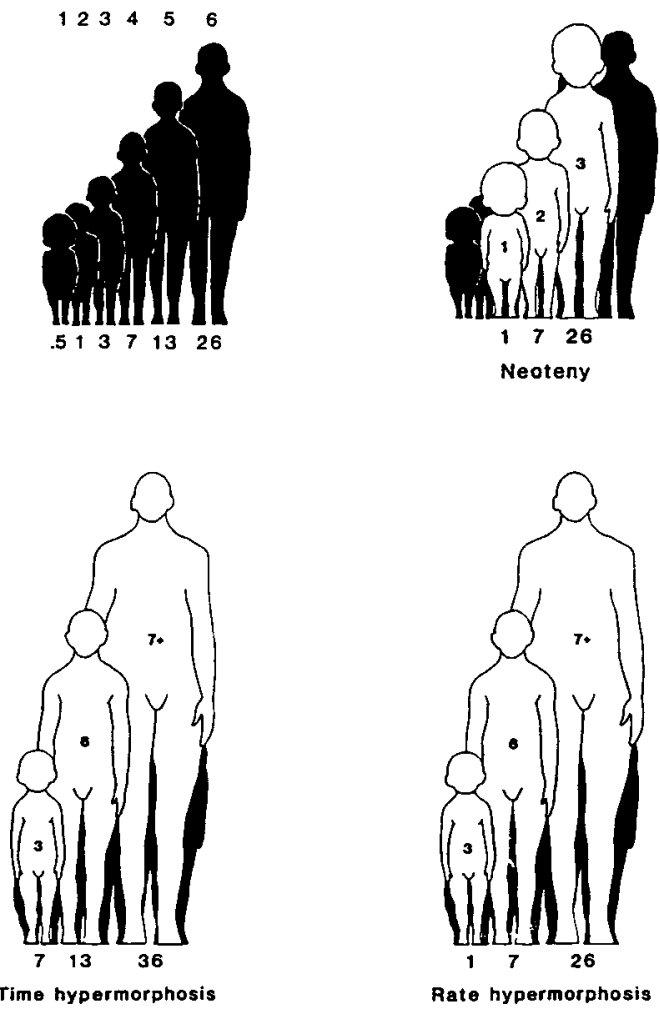

Fig. 6. Silhouettes of size and shape change during human growth. Numbers under silhouettes indicate age in years. Numbers above or on silhouettes indicate relative shape. Top left: Actual size and shape change during normal human development. Top right: Neoteny. Note that at adult size shape 3 is still maintained. Bottom left: Time hypermorphosis. The growth period is extended to 36 years, yielding a peramorphic giant (size and shape of the descendant beyond that of the ancestor). Bottom right: Rate hypermorphosis. Growth ends at age 26 but proceeds at a faster rate, producing another peramorphic giant. Note that in both cases the adult shape at 7+ is outside the range of normal development. Redrawn from Shea (1989), with permission.

(Winter, 1978). Thus, the serum testosterone concentration of the chimpanzee increases about 31-fold from the prepubertal to pubertal state. In the human male, serum testosterone concentration increases about 38-fold, or 1.23 times the increase for the chimpanzee.

According to Watts and Gavan (1982), chimpanzees have a relatively small increase in the velocity of growth of individual long bones during puberty, "usually less than a centimeter" (p. 58), and often less than $0.5 \mathrm{~cm}$. Cameron et al. (1982) per- formed a longitudinal analysis of the growth of individual limb segments in British boys. It was found that in contrast to the negligible velocity change of chimpanzees, the peak value in velocity during the human adolescent growth spurt ranged between $1.34 \mathrm{~cm}$ per year for the forearm and $2.44 \mathrm{~cm}$ per year for the tibia. From these findings one may propose that there are differences in the effect of testosterone on the skeletal growth of chimpanzees and humans. The growth response of the human skeleton to rising testosterone levels is greater than that of the chimpanzee skeleton, since the change in the serum hormone levels of the two primates differs only by a factor of about 1.23 , but the change in the vel ocity of growth differs by a factor of at least 2.0 and as much as 4.9 .

The heterochronic models of neoteny and hypermorphosis predict that a greater or lesser amount of time for growth produces the differences in size and shape between humans and chimpanzees. But these empirical data gathered from growth and endocrine research show that it is the sensitivity of specific skeletal parts to testosterone, determined by DNA and cellular activity, that results in the differences in limb size and shape between adult humans and chimpanzees. The time available for growth is largely irrelevant.

A closer inspection of human cognitive development also fails to support heterochrony, especially Parker's hypermorphosis argument. Human cognitive ontogeny from childhood to adulthood entails the development of new competencies, such as those related to language and social intelligence. The stage theory of Piaget (1954; Piaget and Inhelder, 1969) provides a descriptive and theoretical understanding of the development of human intelligence. The neoteny and hypermorphosis arguments correctly assert that adult humans possess an intellectual plasticity and curiosity usually found only in the young of other species. Piaget's stage theory of human development shows, however, that this is due to the maturation of increasingly sophisticated and flexible cognitive processes, rather than to the retention or extension of infantile or juvenile intellectual abilities. At the physiological 
level, Eccles (1979) shows that the adult human potentials for playfulness, creativity, and intellectual advancement are not derived via heterochrony; rather they are new competencies derived from a constant remodeling, restructuring, and maturation of the neurological architecture in the central nervous system.

The last word on heterochrony, so far at least, is the work of Godfrey and Sutherland (1996). These researchers do not argue for or against one or the other of the many heterochronic mechanisms that may have influenced human evolution. Instead, they develop a quantitative method for the fair testing of any or all heterochrony hypotheses. Their methodology is a major innovation in heterochrony research. They first show that Gould's clock model is based on three mathematically definable vectors for size, shape, and time. Godfrey and Sutherland then show that movement of the clock's hands or age bar may be represented as linear vector distortions. The translation of the clock model to linear vectors makes quantification relatively easy, and, more importantly, allows for the prediction of exact differences between ancestor and descendent species for the different types of heterochrony. The authors carry out several prediction analyses and find that many of the assertions made in the past about the role of heterochrony in human evolution are not correct. In the end, the authors find no support for any currently published heterochronic models for human evolution. Please read Godfrey and Sutherland's article for the details.

\section{THE OTHER SIDE OF THE COIN}

In the tribulations and trials of heterochrony the jury is currently out, and a verdict on what type of heterochrony has shaped which aspects of human growth and development must await new research and testing. F orgotten by all parties in the litigation surrounding heterochrony is another process by which evolution works. I requote Gould, as he stated most succinctly that "evolution occurs when ontogeny is altered in one of two ways: [the first is] when new characters are introduced at any stage of devel opment with varying effects upon sub- sequent stages;" the second is by heterochrony. Much of human evolution, especially the evolution of childhood, is the result of the introduction of new life stages into the general pattern of primate growth and development.

Consider first the general mammalian and primate patterns of growth and then compare these with the human pattern. The majority of mammals progress from infancy to adulthood seamlessly, without any intervening stages, and while their growth rates are in decline (Brody, 1945; Bertalanffy, 1960). This pattern of postnatal growth is illustrated in Figure 7 using data for the mouse. Highly social mammals, such as wolves, wild dogs, lions, elephants, and the primates, postpone puberty by inserting a period of juvenile growth and behavior between infancy and adulthood (Bekoff and Beyers, 1985; Pereiera and F airbanks, 1993). J uveniles may be defined as "prepubertal individuals that are no longer dependent on their mothers (parents) for survival" (Pereira and Altmann, 1985, p. 236). This definition is derived from ethological research with social mammals, especially non-human primates, and applies to the human species as well. J uveniles are not children, as juveniles are independent but children still require care from older individuals. In the highly social mammals, puberty occurs while the rate of growth is still decelerating and there is no readily detectable growth spurt in skeletal dimensions (Fig. 8, but see Tanner et al., 1990, who find that one sample of captive rhesus monkeys have a rate of skeletal growth at puberty that is greater than that of human beings).

Human growth and development from birth to reproductive maturity may be characterized by five stages: 1) infancy, 2) childhood, 3) juvenility, 4) adolescence, and 5) adulthood (Bogin, 1988, 1995; Bogin and Smith, 1996). Thus, humans add childhood and adolescence to the pattern found for primates and other highly social mammals. Each of the human stages of growth can be defined by clear biological and behavioral characteristics, especially those related to rate of growth, feeding, and reproductive behavior. 
Fig. 7. Velocity curves for weight growth in the mouse. In both sexes puberty (vaginal opening for females or spermatocytes in testes of males) occurs just after weaning and maximal growth rate. Weaning (W) takes place between days 15 and 20. After Tanner (1962).
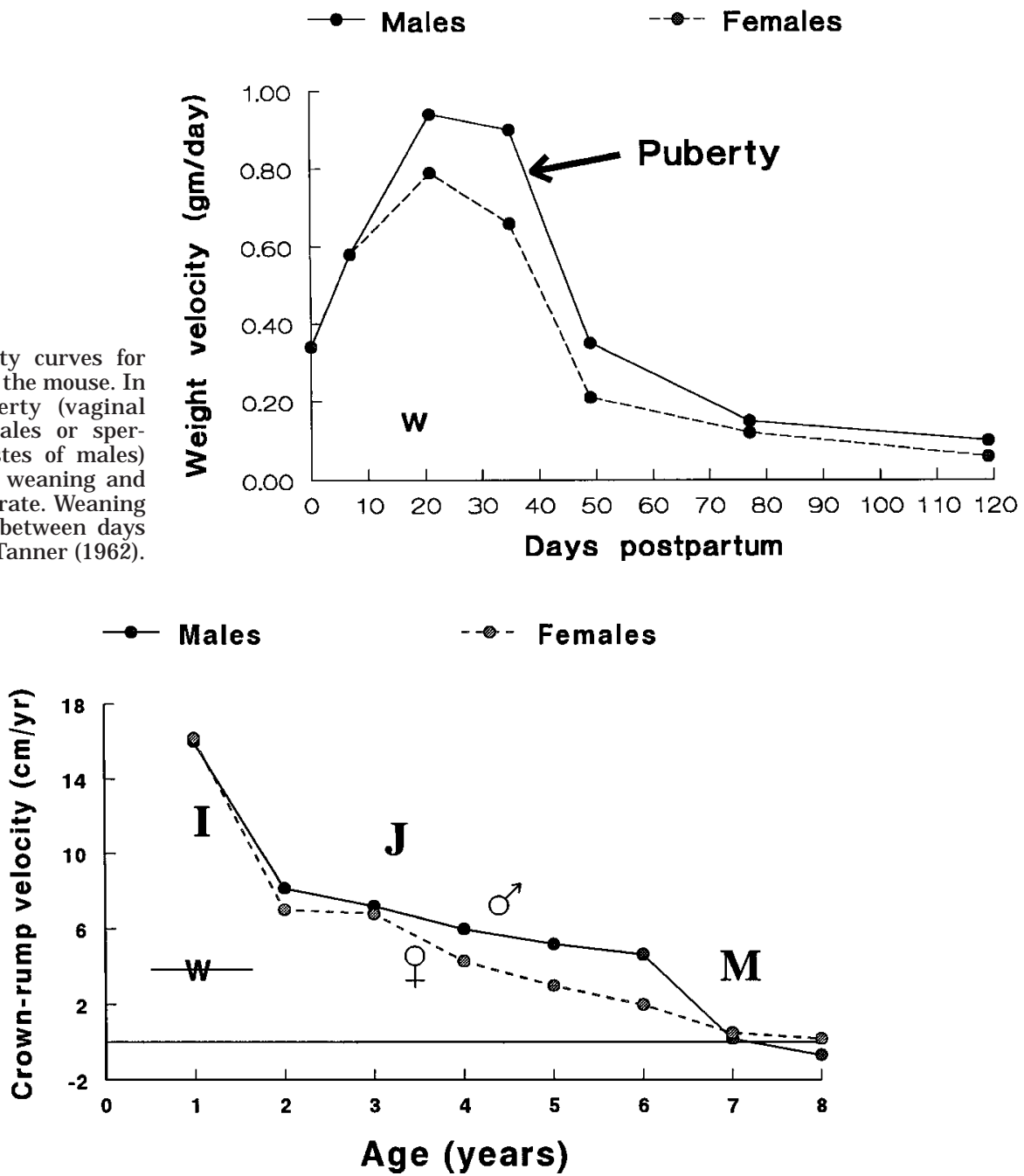

Fig. 8. Baboon crown-rump length velocity. The letters indicate the stages of growth: I, infancy; J, juvenility; $M$, sexual maturity. In the wild the weaning (W) process begins as early as 4 months of age and ends by 12 to 18 months (Altmann, 1980). Puberty begins at about 3.5 years in females ( $(+)$ and 4.5 years in males $(\hat{o})$

\section{RATE OF GROWTH}

Changes in the velocity of growth from birth to adulthood signal the transitions between these five developmental stages. Idealized velocity curves are presented in Figure 1. During infancy growth rate plummets, followed by a period of slower velocity decline in childhood. The end of childhood is often marked by a small increase in vel ocity, called the mid-growth spurt (Tanner, 1947). and ends by about 6.0 years in both sexes. Redrawn with some data smoothing from Coel ho (1985). The patterns of growth for other primate species, including chimpanzees, are similar to these for the baboon (see Bogin, 1988).

Following childhood, therate of growth decelerates during the juvenilestage, and eventually the rate drops to its lowest point since birth. The onset of adolescence is marked by a sudden and rapid increase in growth rate, which peaks at a level unequal ed since early infancy. The mature adult stage begins when growth of the skeleton stops.

The mid-growth spurt is an important feature of human childhood. This spurt is 
associated with an endocrine event called adrenarche, the progressive increase in the secretion of adrenal androgen hormones. Adrenal androgens produce the mid-growth spurt in height, a transient acceleration of bone maturation, and the appearance of axillary and pubic hair, and seem to regulate the development of body fatness and fat distribution (Katz et al., 1985; Parker, 1991). There is a little story that links the midgrowth spurt with neoteny. Louis Bolk (1926), the "father" of the scientific hypothesis for human evol ution via neoteny, speculated that for our early human ancestors sexual maturation took place at about 6 to 8 years of age. The mid-growth spurt was first reported by Backman (1934) and following its discovery, several of Bolk's followers, without any additional supporting evidence, opined that the mid-growth spurt and adrenarche are vestiges of sexual maturation from our evolutionary past. Much research, however, from clinical medicine to anthropological fieldwork, shows that there is little or no connection between adrenarche and sexual maturation, as each are independently control led events (Smail et al., 1982; Weirman and Crowley, 1986; Worthman, 1986; Bogin, 1988, in press; Parker, 1991).

Bolk's idea may be wrong, but a connection with the evolution of the human pattern of growth is still a possibility. The mechanism controlling adrenarche is not understood as no known hormone appears to cause it. There are connections, however, between the production of adrenal hormones, growth, and maturation. Cutler et al. (1978) and Smail et al. (1982) measured the plasma concentration of the adrenal androgens dehydroepiandosterone (DHA), dehydroepiandosterone sulfate (DHAS), and del ta ${ }^{4}$-androstenodine $\left(\mathrm{D}^{4}\right)$ before and after sexual maturation in 14 species. These species include samples of rodents (rat, guinea pig, hamster), domestic animals (rabbit, dog, sheep, pig, goat, horse, cow), primates (macaques-including $76 \mathrm{Macaca}$ mulatta and 80 M. nemestrina-a few baboons, and 52 chimpanzees), and the chicken. The plasma concentrations of DHA, DHAS, and $\mathrm{D}^{4}$ were significantly higher in sexually mature primates species than in any of the other animals. However, the serum level of these adrenal androgens was not related to sexual maturation. Rhesus monkeys aged 1 to 3 years, and not sexually mature, had the same high concentrations of all three adrenal androgens as older, sexually mature monkeys. The same was true for baboons. In contrast, chimpanzees 7 years old or older had adrenal androgen concentrations that were, on average, 4.7 times greater than those for chimpanzees less than 4 years old. Thus, among the animals examined so far, the chimpanzee and the human are the only species that show adrenarche. Only humans are known to have a mid-growth spurt.

The primate data reported by Cutler et al. (1978) and Smail et al. (1982) suggest a possible function for adrenarche. Chimpanzees and humans have low serum levels of adrenal androgens after infancy and prior to adrenarche. Moreover, chi mpanzees and humans have a relatively slow growth and a long delay in the onset of sexual maturation. Perhaps, then, theevolution of reduced adrenal androgen production prior to adrenarche may be explained as a mechanism that maintains slow epiphyseal maturation and skeletal growth in the face of the prolongation of the prepubertal stages of growth. In the human, the delay is so protracted that it becomes possible to insert the childhood stage of development between the infancy and juvenile stages.

Synthesizing all of these data, it is possible to view the combination of adrenarche and the human mid-growth spurt as life history events marking the transition from the childhood to the juvenilestage of growth. In terms of physical growth, the effects of the adrenal androgens, to increase rate of skel etal growth, stimulate body hair growth, and regulate body fat distribution, are shortlived and quite small. Even so, these physical changes may be noticed by the child and his/her intimates, such as parents, and recognized as markers of devel opmental maturation. More to the point is the fact that while adrenarche may have only transient effects on physical development, there is a more permanent and important effect on cognitive function. Psychologists have long been interested in what is called the " 5 to 7 year old shift" in cognition (White, 1965; Rogoff et al., 1975; Whiting and Whiting, 
1975; Weisner and Gallimore, 1977; Whiting and Edwards, 1988; Weisner, 1996). Weisner (1996, p. 295) states that "the 5-7 shift involves changes in internal states and competencies of the maturing child-shifts in cognitive capacities, self concept, visual/ perceptual abilities, or social abilities. The transition marks the emergence of increasing capabilities for strategic and controlled self-regulation, skills at inhibition, the ability to maintain attention and to focus on a complex problem, and planfullness and reflection." Using the terminology of Piaget (Piaget and Inhelder, 1969) the 5-7 shift moves the child from the preoperational to concrete operational stage of cognition. In short, following the shift, the child becomes a juvenile capable of much of his or her own feeding and care. This 5-7 year old shift is found in all cultures so far investigated (Rogoff et al., 1975), and thus seems to be a human species phenomenon. In addition to self-care and -feeding, the juvenile becomes increasingly involved with domestic work and "caretaking interactions with other children" (Weisner, 1996, p. 296). The association of adrenarche, the mid-growth spurt, and the 5-7 shift all seem to mark the progression of the child to the juvenile stage of development.

\section{FEEDING AND BREEDING}

Changes in human feeding and reproductive behavior complement the pattern of human growth velocity. The 5-7 shift is but one example of a change in feeding behavior from dependency to independence. There are other important changes rel ated to feeding between birth, childhood, and the juvenilestage.

\section{Infancy}

As for all mammals, human infancy is the period when the mother provides all or some nourishment to her offspring via lactation. The infancy stage ends when the young mammal is weaned. Weaning is defined here as thetermination of lactation by the mother (other researchers may define weaning as the process of shifting from lactation to eating solid foods). In human societies the age at weaning varies greatly. Industrial- ized societies provide a poor indication of weaning age because bottle-feeding and the manufacture of "baby foods" allow either early termination of breast-feeding or no breast-feeding at all. Preindustrialized human societies provide a better indication of the age at weaning, and hence the transition from infancy to childhood. One study finds that the termination of breast-feeding occurs at a median age of 36 months in these societies (Dettwyler, 1995). Another review of such research (Lee et al., 1991) finds that in so-called "food-enhanced" societies, those where nutritional intake is good, weaning takes place as early as 9 months of age. In "food-limited" societies, wherechronic undernutrition occurs, weaning takes place at 36 months. There are two fascinating corollaries of this comparison. The first is that in both the "food-enhanced" and the "foodlimited" societies the mean weight of weaned infants is about the same, $9.0 \mathrm{~kg}$ and $9.2 \mathrm{~kg}$ respectively, or about 2.7 times birth weight (Lee et al. assume a mean birth weight of $3,400 \mathrm{~g}$ for full-term humans). The second is that some solid foods are introduced into the diet when the infant achieves about 2.1 times birth weight. Lee and colleagues (Lee et al., 1991; Bowman and Lee, 1995) compare the human data with data from 88 species of large-bodied mammals (32 nonhuman primates, 29 ungulates, 27 pinnipeds). They find that for all these species solid food is introduced, again, at about 2.1 times birth weight, but weaning takes place when the infant achieves between 3.2 and 4.9 times birth weight. For all primates the mean value is 4.6 times birth weight (range: 2.3 for Micropithecus talapoin to 9.4 for Gorolla gorilla). The other great apes wean at the following multiples of birth weight: Pan trogl odytes, 4.9; P. paniscus, 6.1; Pongo pygmaeus, 6.4 .

Thus humans are similar to other mammals in that we introduce solid foods at about 2.1 times birth weight. However, humans are unlike other mammals, even other species of primates, in that preindustrial and traditional societies, including "foodlimited" groups such as !Kung huntergatherers, wean at a relatively early stage of growth-before reaching 3.0 times birth weight. 


\section{Childhood}

Childhood is the period following weaning, when the youngster still depends on older peoplefor feeding and protection. Children require specially prepared foods due to the immaturity of their dentition. The deciduous dentition, often called "milk teeth," have thin enamel and shallow roots compared with the permanent dentition. Smith (1991a) and Smith et al. (1994) report that given this dental morphology, young mammals with only the deciduous dentition cannot process the adult-type diet. Smith (1991a) al so finds that for virtual ly all mammals the deciduous dentition is in place during infancy, that is, when the young are nursing. With eruption and occlusion of the first permanent teeth the infant mammal moves either to adulthood (most mammals have only two postnatal growth stages) or to the juvenile stage (social mammals). Smith reports that mammals with some permanent teeth are able to process the adult diet and are independent in terms of feeding. When human infancy ends the deciduous dentition is still in place; thus the human child still requires a special diet and re mains dependent on older individuals for food.

Children also require a special diet due to the small size of their digestive tracts relative to that of the adult (Bogin, 1988). This need can be appreciated most acutely when it is not met. Behar (1977) studied the causes of growth retardation and undernutrition of children living in rural villages in Guatemala. He found that the children had access to sufficient food, but the traditional adult diet of corn and beans did not have the caloric density to meet their growth requirements. Bailey et al . (1984) studied the growth of more than 1,000 infants, children, and juveniles living in 29 villages in northern Thailand. The participants in the study lived in rural agricultural villages, with rice as the basic subsistence crop. The participants were between the ages of 6 months and 5 years at the start of the study, and they were measured about every 6 months for 5 years. It was found that, compared with local or international reference stan- dards for growth, the rural Thai children and juveniles were delayed in growth for all the dimensions studied. Disease histories, parasite infestations, and mortality during infancy and childhood were not significantly associated with growth in this sample. Bailey et al. concluded that the delays in growth were not due to disease or the lack of specific nutrients, such as protein, vitamin $A$, or iron; rather the delays were due to a deficiency in the total intake of calories. The most dramatic falloff in growth occurred at 18 months of age, which corresponds with the average age at weaning in these villages. Weaning foods were usually watered-down versions of adult foods. Although there were no food shortages in the villages, Bailey et al. reason that the small gastrointestinal tracts of the weaned infants and young children may not have been capable of digesting enough food to meet their caloric demands for maintenance and growth of the body. These two studies (and others reviewed in Bogin, 1988) show that without the use of appropriate weaning foods children will suffer calorie insufficiency leading to undernutrition, developmental delays, and growth retardation.

Another reason that children need a special high-energy diet is the rapid growth of their brain (Fig. 2). Leonard and Robertson (1992) estimate that due to this rapid brain growth, "a human child under the age of 5 years uses $40-85$ percent of resting metabolism to maintain his/her brain [adults use 16-25 percent]. Therefore, the consequences of even a small caloric debt in a child are enormous given the ratio of energy distribution between brain and body" (p. 191). In a related study, Leonard and Robertson (1994) also show that the size of the human brain relative to total body size necessitates an energy-dense diet. At all stages of life after birth, human beings have brains that are significantly larger than expected given the human body size (Figs. 2 and 9). Aiello and Wheeler (1995) refine the relationship between human brain size and body size by noting that compared with other mammals, including monkeys and apes, humans have exceptionally small gastrointestinal tracts (guts) relative to brain size. Aiello and 
Fig. 9. Adult body weight and brain weight plotted for 61 species of Cercopithecidae (Old World monkeys), apes, and humans. The curve is logarithmic regression fit to the data for all species. The illustration is a sagital section of the human brain. Each part of the human brain enlarged during evolution, especially the size of cerebral cortex (data from Harvey et al., 1987).

Wheel er show that both brain tissueand gut tissue are "expensive," meaning that both types of tissue have relatively high metabolic rates. They present estimates of the percentage of total body basal metabolic rate for several tissues utilized by the typical 65 $\mathrm{kg}$ adult human male. For the brain the value is 16.1 percent and for the gut the value is 14.8 percent. Given these values, Aiello and Wheel er propose that during human evolution the gut reduced in size as a trade-off allowing, in part, for expansion of brain size. Both Leonard and Robertson (1994) and Aiello and Wheeler conclude that given this brain to body size/gut size relationship, adult humans require a diet that is nutrient-dense, especially in energy, and easy to digest. Children, of course, have a relatively larger disproportion between brain size and body/gut size than do adults (Fig. 2). Added together, each of these constraints of childhood, an immature dentition, a small digestive system, and a calorie-demanding brain that is both relatively large and growing rapidly, necessitates a special diet that must be procured, prepared, and provided by older individuals.

\section{Juvenility}

Important developments that allow children to progress to the juvenile stage of growth and development are the eruption of the first permanent molars and completion of growth of the brain (in weight). First molar eruption takes place, on average, between the ages of 5.5 and 6.5 years in most human populations ( $\mathrm{aswal}$, 1983; Smith, 1992). Functional occlusion occurs some weeks to months thereafter. Recent mor phological and mathematical investigation shows that brain growth in weight is complete at a mean age of 7 years (Cabana et al., 1993). Thus, significant milestones of dental and brain maturation take place at about 7 years of age. At this stage of development the child becomes much more capable of processing dentally an adult-type diet (Smith, 1991a). Furthermore, nutrient requirements for the maintenance and the growth of both brain and body diminish to less than 50 percent of total energy needs. Finally, the child shifts to a new plateau of cognitive function.

The child then progresses to the juvenile stage. As described above, ethnographic and psychological research shows that juvenile humans have the physical and cognitive abilities to provide much of their own food and to protect themselves from environmental hazards such as predation (children are especially vulnerable to predation due to small body size) and disease (Weisner, 1987; Blurton-J ones, 1993). In girls, the juvenile period ends, on average, at about the age of 10. This is 2 years before it usually ends in 
boys, the difference reflecting the earlier onset of puberty in girls.

\section{Adolescence}

Human adolescence begins with puberty, marked by some visible sign of sexual maturation such as increased density of pubic hair (indeed the term is derived from the Latin pubescere: to grow hairy). The adolescent stage also includes development of the secondary sexual characteristics and the onset of interest and activity in adult patterns of sociosexual and economic behavior. These physical and behavioral changes of puberty occur in many species of mammals. What makes human adolescence different is that during this life stage both boys and girls experience a rapid acceleration in the growth of virtually all skeletal tissue-the adolescent growth spurt. Human adolescence and the growth spurt are treated in detail in other publications (Bogin, 1988, 1994a, 1995; Bogin and Smith, 1996).

\section{Adulthood}

Adolescence ends and early adulthood begins with thecompletion of the growth spurt, the attainment of adult stature, the comple tion of dental maturation (eruption of the third molar, if present), and the achievement of full reproductive maturity (Figs. 1 and 2). The latter includes both physiological, socioeconomic, and psychobehavioral attributes, which all coincide, on average, by about age 19 in women and 21 to 25 years of age in men (Bogin, 1988, 1993, 1994a). That is, these are the median ages at first birth for women or age at fatherhood for men on a worldwide basis for both contemporary and historic populations.

\section{EMPIRICAL AND MATHEMATICAL EVIDENCE AGAINST HETEROCHRONY}

Clearly, the human pattern of growth from birth to maturity is qualitatively and quantitatively different from the pattern for other primates. The quantitative differences can be expressed in amounts, rates, and timing of growth events, and are so reported in many standard textbooks of human growth (e.g., Tanner, 1962; Bogin, 1988). These quantitative differences may also be expressed in terms of the type and number of mathematical functions that are needed to describe growth. The distance and velocity curves for most mammalian species can be estimated by a single function, such as a simple polynomial or exponential function. Even the monkeys and apes, with the addition of the juvenile stage, require no more than two such relatively simple functions (Laird, 1967; Bogin, 1988). The insertion of the mid-childhood and adolescent spurts into human ontogeny means that at least three mathematical functions are needed to adequately describe shape of the velocity curve (Fig. 10). Not only more, but also more complex functions are needed (Bock and Thissen, 1976; Karlberg, 1985). It is vitally important to stress here that all of this quantitative knowledge of the biology of human growth is well established and widely available. This information unequivocally negates neoteny, hypermorphosis, or any other single heterochronic process as the primary process of human evolution. Lamentably, the works on neoteny cited abovewith the exception of Shea's work-make little or no reference to studies of the physical growth and development of living people.

\section{HOW AND WHEN DID THE HUMAN PATTERN EVOLVE?}

The stages of the life cycle may be studied directly only for living species. However, there are lines of evidence on the life cycle of extinct species. Such inferences for the hominids are, of course, hypotheses based on comparative anatomy, comparative physiology, comparative ethology, and archaeology. Examples of this methodology are found in the work of Martin (1983) and Harvey et al. (1987) on patterns of brain and body growth in apes, humans, and their ancestors.

Apes have a pattern of brain growth that is rapid before birth and relatively slower after birth. In contrast, humans have rapid brain growth both before and after birth (Fig. 11). This difference may be appreciated by comparing ratios of brain weight divided by total body weight (in grams). At birth this ratio averages 0.09 for the great apes and 0.12 for human neonates. At adulthood the ratio averages 0.008 for the great apes and 0.028 for humans. In other words, relativeto 


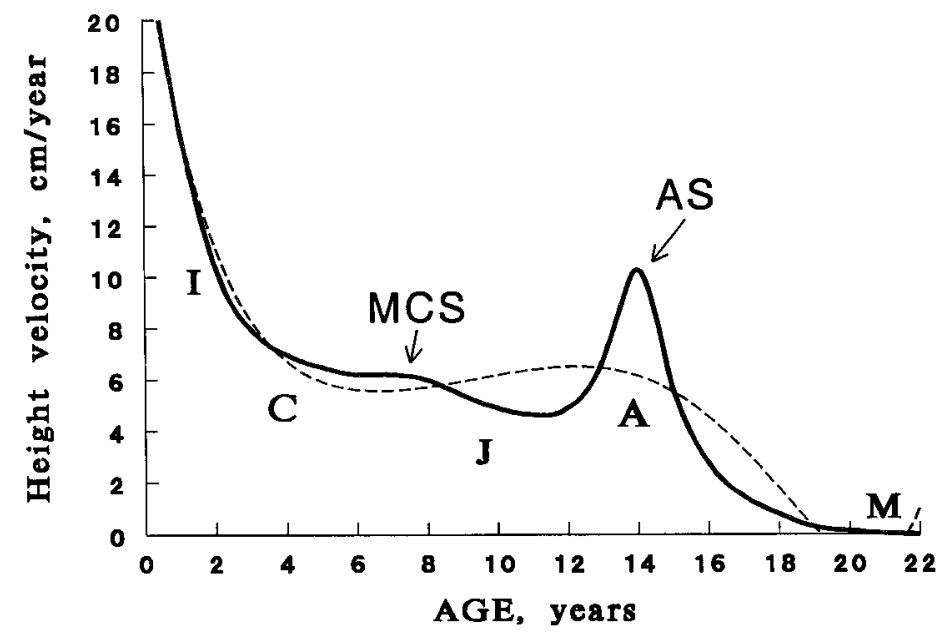

Fig. 10. Idealized velocity curve of human growth for boys (solid line): I, infancy; C, childhood; J , juvenility; A, adolescence; $M$, mature adult. The dashed line is a sixth-degree polynomial curve fit to the velocity curve data. The polynomial curve does not fit well to real growth data due to the pulses of the mid-childhood spurt (MCS) and the adolescent spurt (AS). The human velocity curve cannot be fit adequately by a single continuous mathematical function. At a minimum, three functions are required.

body size human neonatal brain size is 1.33 times larger than the great apes, but by adulthood the difference is 3.5 times. The human-ape difference is not due to any single heterochronic process, that is, not the result of delay, prolongation, or acceleration of a basic ape-like pattern of growth. Rather it is due to new patterns of growth for the human species. The rate of human brain growth exceeds that of most other tissues of the body during the first few years after birth (Fig. 2). Martin (1983) and Harvey et al. (1987) also show that human neonates have remarkably large brains (corrected for body size) compared with other primate species. Together, relatively large neonatal brain size and the high postnatal growth rate give adult humans the largest encephalization quotient (an allometric scaling of brain to body size) of all higher primates (Fig. 9).

Martin (1983) hypothesizes that a "humanlike" pattern of brain and body growth becomes necessary once adult hominid brain size reaches about $850 \mathrm{cc}$. This biological marker is based on an analysis of cephalopelvic dimensions of fetuses and their mothers across a wide range of social mammals, including cetaceans, extant primates, and fossil hominids (Martin, 1983). Given the mean rate of postnatal brain growth for living apes, an 850-cc adult brain size may be achieved by all hominoids, including extinct hominids, by lengthening the fetal stage of growth. At brain sizes above $850 \mathrm{cc}$ the size of the pelvic inlet of the fossil hominids, and living people, does not allow for sufficient fetal growth. Thus, a period of rapid postnatal brain growth and slow body growth-the human pattern-is needed to reach adult brain size.

Martin's analysis is el egant and tenable. Nevertheless, the difference between ape and human brain growth is not only a matter of velocity; it is also a matter of life history stages. Brain growth for both apes and humans ends at the start of the juvenile stage, which means that apes complete brain growth during infancy. Humans, however, insert the childhood stage between the infant and juvenile stages. Childhood may provide the time and the continuation of parental investment, necessary to grow the larger human brain. Following this line of reasoning, any fossil human, or any of our fossil hominid ancestors, with an adult brain size above Martin's "cerebral Rubicon" of 850 cc may have included a childhood stage of growth as part of its life history. 


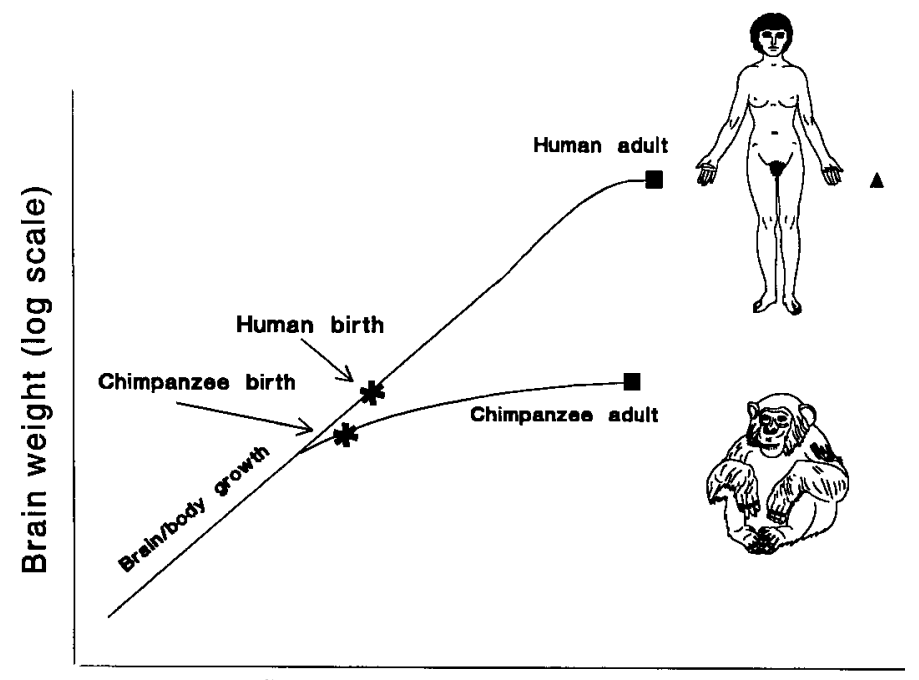

Body weight (log scale)

Fig. 11. Growth curve for human brain and body compared to that of the chimpanzee. The length of the human fetal phase, in which brain and body grow at the same rate for both species, is extended for humans. Chimpanzee brain growth slows after birth, but humans maintain the high rate of brain growth during the

Given this background, Figure 12 is my Schultz-inspired summary of the evolution of the human pattern of growth and development from birth to age 20 years (the evolution of adolescence is not discussed in this article, but see Bogin, 1993, 1994a, and Bogin and Smith, 1996). Figure 12 must be considered as "a work in progress," as only the data for the first and last species (Pan and Homo sapiens) are known with some certainty. The patterns of growth of the fossil hominid species are reconstructions based on published analyses of skel etal and dental development of fossil specimens that died before reaching adulthood (see Smith, 1991b, 1992; Bogin and Smith, 1996, for reviews of this literature). One major message to take from the figure is that the prolongation of the total time for growth that plays such a prominent role in the hypotheses of neoteny and hypermorphosis is definitely a part of human evolution. However, time prolongation is not sufficient to account for the insertion of the new stages of childhood and adolescence that are part of human growth.

Australopithecus afarensis is considered by most paleontologists to be a hominid, but postnatal phase. In contrast, the rate of human body growth slows after birth. If the human brain/body growth rate were equal to the chimpanzee rate, then adult humans would weigh $454 \mathrm{~kg}$ and stand nearly 3.1 $\mathrm{m}$ tall (indicated by the $\mathbf{\Delta}$ ). After Martin (1983).

shares many anatomical features with nonhominid pongid species including an adult brain size of about $400 \mathrm{cc}$ (Simons, 1989) and a pattern of dental development indistinguishable from extant apes (Smith, 1991b). Therefore, the chimpanzee and $A$. afarensis are depicted in Figure 12 as sharing the typical tripartite stages of postnatal growth of social mammals-infant, juvenile, adult (Pereira and Fairbanks, 1993). To achieve the larger adult brain size of $A$. africanus (442 cc) may have required an addition to the length of the fetal and/or infancy periods. The rapid expansion of adult brain size during the time of Homo habilis (650 to 800 cc) might have been achieved with further expansion of both the fetal and infancy periods, as Martin's "cerebral Rubicon" was not surpassed. However, the insertion of a brief childhood stage into hominid life history may have occurred. This conjecture is based on a comparison of human and ape reproductive strategies.

There are limits to amount of delay between birth and sexual maturity, and between successful births, that any species can tolerate. The great apes are examples of this limit. Chimpanzee females in the wild reach 
Fig. 12. The evolution of

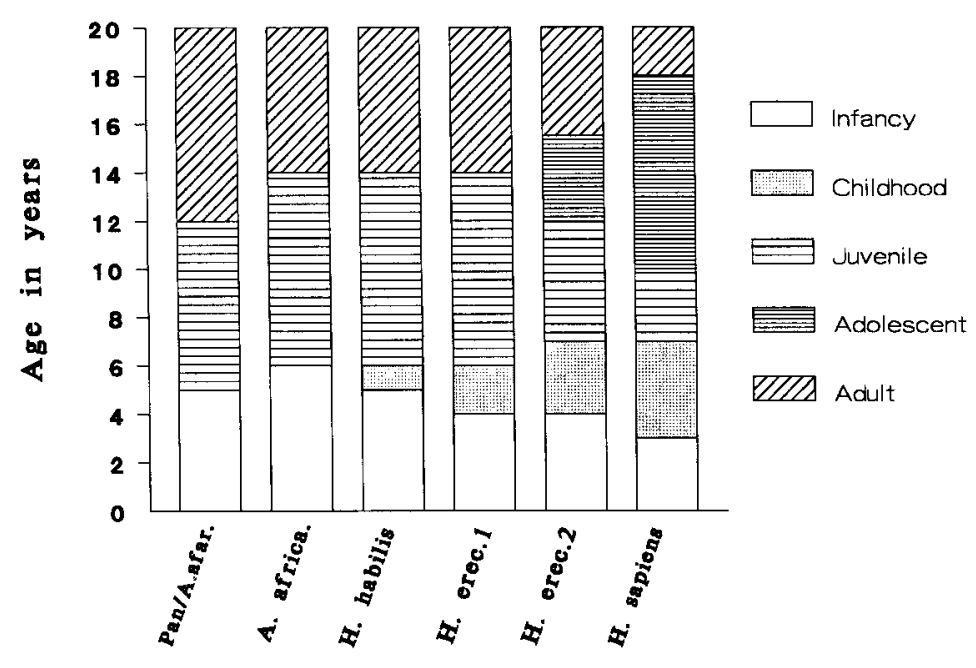
Fig first 20 years of life. Abbreviated nomenclature as follows: A. afar., Austral opithecus afarensis; A africa., Austral opithecus africanus; $\mathrm{H}$. habilis, Homo habilis; $H$. erec. 1, early Homo erectus; $H$. erec. 2, late Homo erectus; $\mathrm{H}$. sapiens, Homo sapiens.

menarche (the first menstruation) at 11 to 12 years of age and have their first births at an average age of 14 years (Goodall, 1983). Theaverage period between successful births in the wild is 5.6 years and young chimpanzees are dependent on their mothers for about 5 years (Teleki et al., 1976; Goodall, 1983; Nishida et al., 1990). Actuarial data collected on wild-living animals indicate that between 35 percent (Goodall, 1983) and 38 percent (Nishida et al., 1990) of all live-born chimpanzees survive to their mid-20s. Although this is a significantly greater percentage of survival than for most other species of animals, the chimpanzee is at a reproductive threshold. Goodall (1983) reports that for the period 1965 to 1980 there were 51 births and 49 deaths in one community of wild chimpanzees at the Gombe Stream National Park, Tanzania. During a 10-year period at the Mahale Mountains National Park, Tanzania Nishida et al. (1990) observed "74 births, 74 deaths, 14 immigrations and 13 emigrations" in one community. Chimpanzee population growth is, by these data, effectively equal to zero. Gal dikas and Wood (1990) present data for the orangutan that show that these apes are in a more precarious situation. Compared with the 5.6 years between successful births of chimpanzees, the orangutan female waits up to 7.7 years, and orangutan populations are in decline. Lovejoy (1981) calls the plight of great ape reproduction a "demographic dilemma" (p. 211).
The great apes, and fossil hominids such as Austral opithecus or early Homo, seem to have reached this demographic dilemma by extending infancy, forcing a demand on nursing to its limit (Fig. 12). Extending infancy and birth intervals beyond the chimpanzee/ Austral opithecus range may not have been possible if hominids such as Homo habilis were to remain extant. Early Homo may have overcome this demographic dilemma by reducing the length of infancy and inserting childhood between the end of infancy and the juvenile period. Free from the demands of nursing and the physiological brake that frequent nursing places on ovulation (Ellison, 1990), mothers could reproducesoon after their infants became children. This certainly occurs among modern humans. An often cited example, the !Kung, are a traditional hunting and gathering society of southern Africa. A !K ung woman's age at her first birth averages 19 years and subsequent births follow about every 3.6 years, resulting in an average fertility rate of 4.7 children per woman (Howell, 1979; Short, 1976). Women in another hunter-gather society, the Hadza (Blurton-J ones et al., 1992), have even shorter intervals between successful births, stop nursing about 1 year earlier, and average 6.15 births per woman. For these reasons a brief childhood stage for Homo habilis is indicated in Figure 12.

Further brain size increase occurred during $\mathrm{H}$. erectus times. The earliest adult specimens have brain sizes of 850 to $900 \mathrm{cc}$. 
This places $\mathrm{H}$. erectus at or above Martin's "cerebral Rubicon" and seems tojustify insertion and/or expansion of the childhood period to provide the biological time needed for the rapid, human-like, pattern of brain growth. It should be noted from Figure 12 that the model of human evolution proposed here predicts that from the Austral opithecus to the $\mathrm{H}$. erectus stage the infancy period shrinks as the childhood stage expands. If the infancy stage did in fact shrink, $\mathrm{H}$. erectus, and all later hominids, would have enjoyed an even greater reproductive advantage over all other hominids. Later $\mathrm{H}$. erectus, with adult brain sizes up to $1,100 \mathrm{cc}$, are depicted with further expansion of childhood and the insertion of the adolescent stage. In addition to bigger brains, the archaeol ogical record for later $\mathrm{H}$. erectus shows increased complexity of technology (tools, fire, and shelter) and social organization (Klein, 1989). These techno-social advances are likely to be correlates of changes in bi ol ogy and behavior associated with further development of the childhood stage of life (Bogin and Smith, 1996). The evolutionary transition to archaic and finally modern $\mathrm{H}$. sapiens expands the childhood stage to its current dimension.

\section{WHO BENEFITS FROM CHILDHOOD?}

Brain sizes of extant and fossil hominoids provide some idea of when human life stages may have evolved, but do not explain why they evolved. Bonner (1965) shows that the presence of a stage, and its duration, in the life cycle relate to such basic adaptations as locomotion, reproductive rates, and food acquisition. To make sense out of the pattern of human growth one must look for the "basic adaptations" that Bonner describes. The most basic of these adaptations are those that relate to evolutionary success. This is traditionally measured in terms of the number of offspring that survive and reproduce. Biological and behavioral traits do not evolve unless they confer upon their owners some degree of reproductive advantage, in terms of survivors a generation or more later. Bogin (1988) lists seven reasons for the evolution of human childhood from the perspective of reproductive success. The first three are the traditional "textbook" explanations that emphasize learning, an idea that goes back at least to Spencer (1886), and even further back, to the dawn of written history (Boyd, 1980). These three traditional explanations are that childhood provides for: 1) an extended period for brain growth; 2) time for the acquisition of technical skills, e.g. toolmaking and food processing; and 3) time for socialization, play, and the development of complex social roles and cultural behavior.

These reasons are valid inasmuch as they confer an advantageto preadult individuals. However, this brain-learning list of explanations cannot account for the initial impetus for the insertion of childhood into human life history. A childhood stage of devel opment is not necessary for the type of learning listed here. The prolonged infancy and juvenile period of the social carnivores (Bekoff and Beyers, 1985) and apes (Bogin, 1994b) can serve that function. Rather, childhood may be better viewed as a feeding and reproductive adaptation for the parents of the child, as a strategy to elicit parental care after infancy, as a strategy to minimize the risks of starvation for the child, a means of shifting the care of offspring from the parents, especially the mother, to juveniles and older, postreproductive, adults (i.e., grandmothers), and as a mechanism that allows for more precise "tracking" of ecological conditions via developmental plasticity during the growing years.

Thus in addition to the three "textbook" explanations given above, there are at least five additional reasons for the evolution of childhood (these update or replace reasons 4-7 in Bogin, 1988), as follows.

1) Childhood is a feeding and reproductive adaptation. A childhood growth stage may have originally evolved as a means by which the mother, the father, and other kin could provision dependent offspring with food. This frees the mother from the demands of nursing and the inhibition of ovulation related to continuous nursing. This decreases the interbirth interval and increases reproductive fitness.

Figure 13 is a comparison of several life history events for female great apes and humans. The data are drawn from studies of wild-living animals for the great apes and 
non-contracepting hunting and gathering or horticultural populations for humans (citation in the figure legend). Based on this figure it is possible to reiterate and strengthen some points made above about ape and human reproductive patterns. Note that the infancy dependency period for each of the apes species is longer than that for humans. Ape infancy ends after eruption of the first permanent molar, which is probably a requirement so that the juvenile ape can acquire and process foods of the adult diet (Smith, 1991a). Human infancy ends before eruption of the first permanent molar, that is, before the youngster can process adult foods. The evolution of childhood as a stage in human life history "fills the gap" between the infant's dependency on the mother for food via nursing and the feeding independence of the juvenile. Note also from Figure 13 that compared with the apes, the addition of a childhood stage and the prolongation of the juvenile and adolescent stages of development for humans delay the age of both menarche and first birth. However, compared with the great apes, humans have the potential to reduce the birth spacing interval and, therefore, as discussed above, each woman may produce more offspring during her life than any female ape. This results in an increase in reproductivefitness if the additional offspring survive to maturity. !Kung, Hadza, and all human parents help to ensure survival of their offspring by provisioning all their children with food, not just their current infant, for a decade or longer. The child must be given foods that are specially chosen and prepared and these may be provided by older juveniles, adolescents, or adults. In Hadza society, for example, grandmothers and great-aunts are observed to supply a significant amount of food to children (Blurton-J ones, 1993). In Agta society (Philippine hunter-gathers) women hunt large game animals but still retain primary responsibility for child care. They accomplish this by living in extended family groups-two or three brothers and sisters, their spouses, children and parentsand sharing the child care (Estioko-Griffin, 1986). Women of all ages work together in food preparation, manufacture of clothing, and child care. In all of these hunter-gather societies, juvenile girls associate with these working groups and the girls provide much of the direct care and feeding of children, but always under the guidance of adolescents and adults. In some soci eties fathers provide significant child care, including the Agta, who take their children on hunting trips, and the Aka Pygmies, a hunting-gathering people of central Africa (Hewlitt, 1991). Summarizing the data from many human societies, Lancaster and Lancaster (1983) call this type of child care and feeding "the hominid adaptation," for no other primate or mammal does this.

2) A stimulus to release these parental behaviors toward children may be found in the very pattern of growth of the children themselves, in that the allometry of the growth of the human child releases nurturing and caregiving behaviors in older individuals. The central nervous system, in particular the brain, follows a growth curve that is advanced over the curve for the body as a whole (Fig. 2). The brain achieves adult size when body growth is only 40 percent complete, dental maturation is only 58 percent complete, and reproductive maturation is only 10 percent complete. The all ometry of the growth of the human child maintains an infantile appearance (large cranium, small face and body, little sexual development), which stimulates nurturing and care-giving behaviors in older individuals. A series of ethological observations (Lorenz, 1971) and psychological experiments (Todd et al., 1980; Alley, 1983) demonstrate that these growth patterns of body, face, and brain allow the human child to maintain a superficially infantile (i.e., "cute") appearance longer than any other mammalian species (see Box 1 ). The infantile appearance of children facilitates parental investment by maintaining the potential for nurturing behavior of older individuals toward both infants and dependent children (Bogin, 1988, 1990; McCabe, 1988).

3) Children are relatively inexpensive to feed. The relatively sl ow rate of body growth and small body size of children reduces competition with adults for food resources, because slow-growing, small children require less total food than bigger individuals. A 5-year-old child of average size (the 50th 


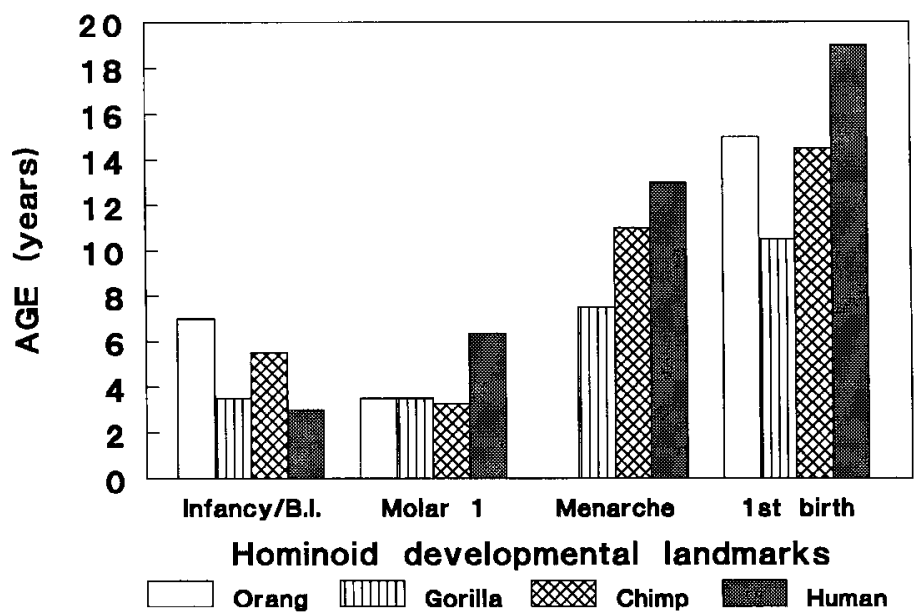

Fig. 13. Hominoid developmental landmarks. Data based on observations of wild-living individuals, or for human, healthy individuals from various cultures. Note that compared with apes, humans experience developmental delays in eruption of the first permanent molar, age at menarche, and age at first birth. However, humans have a shorter infancy and shorter birth interval, which in apes and traditional human societies are virtually coincident. The net result is that humans have the potential for greater lifetime fertility than any ape. Species abbreviations are: Orang, Pongo pygmaeus

centile of the NCHS reference curves for growth) and activity, for example, requires 22.7 percent less dietary energy per day for maintenance and growth than a 10-year-old juvenile on the 50th growth centile (Ulijaszek and Strickland, 1993; Guthrie and Picciano, 1995). Thus, provisioning children, though time consuming, is not as onerous a task of investment as it would be, for instance, if both brain and body growth were both progressing at the same rapid rate. Moreover, in times of food scarcity children are protected from starvation by this unique pattern of brain and body growth.

4) Thetask of child care becomes even less onerous because "babysitting" is possible Since children do not require nursing any competent member of a social group can provide food and care for them. Early neurological maturity vs. late sexual maturity allows juveniles and young adolescents to provide much of their own care and also provide care for children (Bogin, 1994a). Grandmothers and other postreproductive women also provide much child care (Bogin and Smith, 1996). Again, this frees younger
Gorilla, Gorilla gorilla; Chimp, Pan troglodytes; Human, Homo sapiens. Developmental landmarks are: Infancy/B.I., period of dependency on mother for survival, usually coincident with mean age at weaning and/or a new birth (B.I., birth interval); Molar 1, mean age at eruption of first permanent molar; Menarche, mean age at first estrus/menstrual bleeding; 1st birth, mean age of females at first offspring delivery. Sources: Bogin (1988, 1994a), Galdikas and Wood (1990), Nishida et al. (1990), Smith (1992), Watts and Pusey (1993).

adults, especially the mother, for subsistence activity, adult social behaviors, and further childbearing.

5) A further important reason for the evolution of childhood is that childhood allows for developmental plasticity. Following the discussion in Stearns (1992) and MascieTaylor and Bogin (1995), the term plasticity means a potential for change in the phenotype of the individual caused by a change in the environment. The fitness of a given phenotype varies across the range of variation of an environment. When phenotypes are fixed early in development, such as in mammals that mature sexually soon after weaning (e.g., rodents), environmental change and high mortality are positively correlated. Social mammals (carnivores, elephants, primates) prolong the developmental period by adding a juvenile stage between infancy and adulthood. Adult phenotypes develop more slowly in these mammals. They experience a wider range of environmental variation, and the result is a better conformation between the individual and the environment. Fitness is increased in 
that more offspring survive to reproductive age than in mammalian species without a juvenile stage (Lancaster and Lancaster, 1983; Pereira and Fairbanks, 1993). Humans insert the childhood stage between infancy and the juvenile period. This results in an additional 4 years of relatively slow physical growth and allows for behavioral experience that further enhances developmental plasticity. The combined result is increased fitness (reproductivesuccess). Lancaster and Lancaster (1983) report that humans in traditional societies, such as hunters and gatherers and horticulturalists, rear about 50 percent of their live-born offspring to adulthood. In contrast, the Lancaster and Lancaster find that monkeys and apes rear between 12 and 36 percent of live-born offspring to adulthood. The initial human advantage may seem small, but it means that between 14 to 38 more people survive out of every 100 born-more than enough over the vast course of evolutionary time to make the evolution of human childhood an overwhelmingly beneficial adaptation.

\section{CONCLUSION}

These five themes of childhood-feeding, nurturing, low cost, babysitting, and plasticity-account for much of the evolution of and pattern of growth of our species. Understanding these themes hel ps to resolve the paradox of human growth and evolution-lengthy development and low fertility. In reality humans raise a greater percentage offspring to adulthood than any other species. These successfully reared young adults then begin their own reproduction and thus ensure some "intimation of immortality" for their parents. In the center of it all is human childhood. For the child is indeed, to paraphrase Wordsworth, parent to the reproductively successful and well-adapted adult.

\section{BOX 1: THE EVOLUTIONARY PSYCHOLOGY OF CHILDHOOD}

Reproductive success is the major force behind the evolution of all species. Part of the reproductive success of the human species is due to the intense investment and care that parents, and other individuals, lavish on infants and children. In the course of human evolution, at least sincetheappear- ance of the genus $\mathrm{H}$ omo in the last 2 million years, patterns of growth were shaped by natural selection to promote and enhance parental investment. One way this was accomplished was by stimulating what may be called the "psychol ogy of parenting."

Lorenz (1971) stated that the physical characteristics of mammalian infants, including small body size, a relatively large head with little mandibular or nasal prognathism, relatively large round eyes in proportion to skull size, short thick extremities and clumsy movements, inhibit aggressive behavior by adults and encourage their caretaking and nurturing behaviors. Lorenz believed that these infantile features trigger "innate releasing mechanisms" in adult mammals, including humans, for the protection and care of dependent young. Gould (1979) questions the innateness of the human response to infantile features. Such behavior may be "learned from our immediate experience with babies and grafted upon an evolutionary predisposition for attaching ties of affection to certain learned signals" (p. 34). The important point is that whether innate or learned the resultant behavior is the same.

There seems to be a pan-human ability to perceive the five stages of human postnatal development and respond appropriately to each. An elegant series of experiments performed by Todd and his colleagues (1980) show that human perceptions of body shape and growth status are consistent between individuals. When adult subjects (about 40 college students, all childless) were shown a series of profiles of human skull proportions, they could easily arrange them correctly into a hierarchy spanning infancy to adulthood. The subjects could also ascribe maturity ratings to skull profiles that were geometrical ly transformed to imitate the actual changes that occur during growth (Fig. B1.1). This perception was selective because a variety of other types of geometrical transformations elicited no reports of growth or maturation. When the growth-like mathematical transformations were applied to profiledrawings of the heads of birds and dogs, human subjects reported identical perceptions of growth and maturation, even though in reality the development of these animals does 
CARDIOIDAL
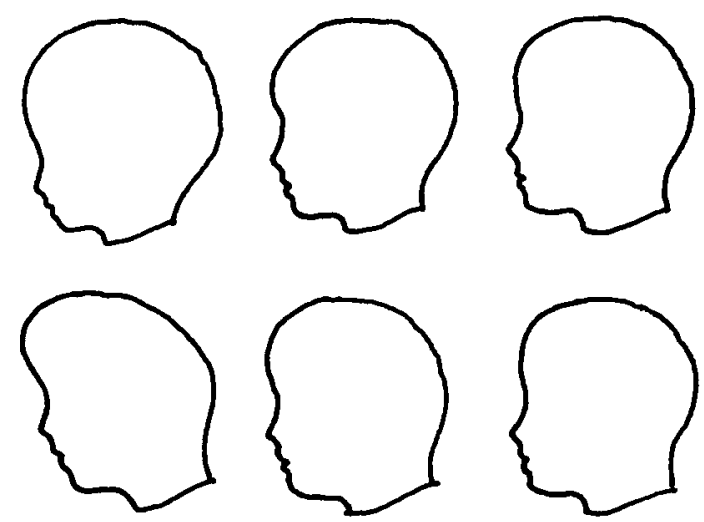

STRAIN
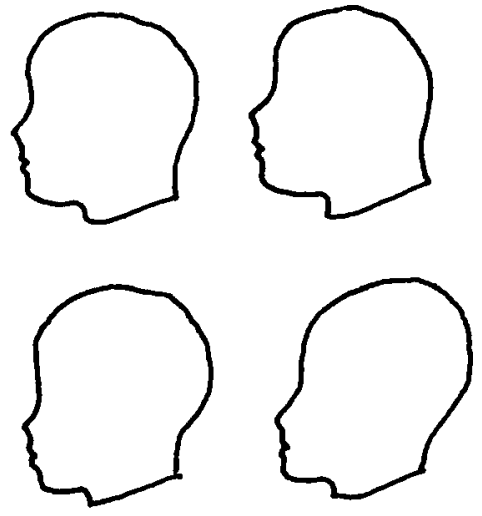

AFEINE: SHEAR

Fig. B1.1. Two of the mathematical transformations of human head shape used in the experiments of Todd et al. (1980). The middle profile in each row was drawn from the photograph of a 10-year-old boy. The transformations were applied to this profile of a real child. The cardioidal strain transformation is perceived by most adults as growth. The affine shear transformation is not perceived as growth.

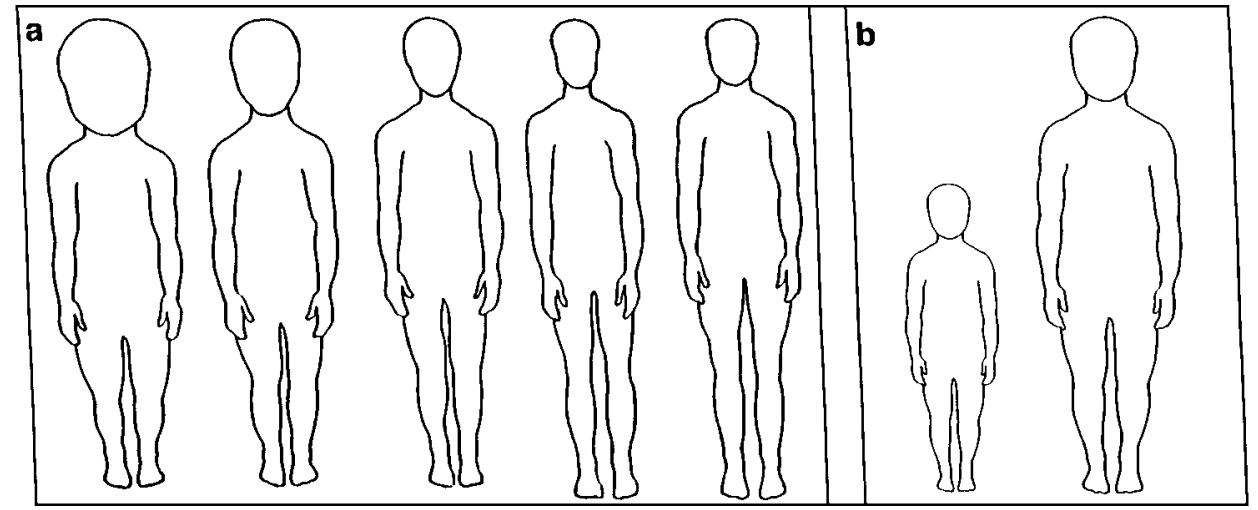

Fig. B1.2. a: The series of five shape-variant drawings used in the experiments of Alley (1983). These drawings show thetypical body proportions of a maleat (from left) birth, 2, 6, 12, and 25 years of age. b:An example of the size-variant pairs of drawings used in the experiments of Alley (1983).

not follow the human pattern of skull-shape change. Even more surprising is that subjects reported the perception of growth when the growth-like mathematical transformations were applied to front and side view profiles of Volkswagen "beetles," objects that do not grow.

In another series of experiments, Alley (1983) studied the association between human body shape and size, and the tendency by adults to protect and "cuddle" other indi- viduals. In the first experiment, subjects were shown two sets of drawings. One set was based upon two-dimensional diagrams depicting changes in human body proportion during growth. Alley's version of these diagrams are called "shape-variant" drawings (Fig. B1.2a). Alley's second set of figures were called "size variant" drawings (Fig. B1.2b). He used the middle-most, "6-yearold" profile in the shape-variant series to construct sets of figures that varied in height 
TABLE B1.1. Mean (and standard deviation) reported willingness to defend or cuddle persons of different body proportions (Alley, 1983)

\begin{tabular}{ccc}
\hline Age portrayed (years) & Defend & Cuddle \\
\hline Newborn & $7.7(1.7)$ & $3.4(2.3)$ \\
2 & $7.1(1.7)$ & $3.4(2.0)$ \\
6 & $5.8(1.8)$ & $3.2(2.2)$ \\
12 & $5.0(1.9)$ & $3.0(1.9)$ \\
25 & $4.3(1.9)$ & $2.7(2.2)$ \\
\hline
\end{tabular}

and width, but not in shape. Note that these figures have no facial features or genitals. Perceptual differences between figures are due to body shape or size al one.

In the first experiment, the subjects were shown pairs of the shape-variant drawings (i.e., profiles of a newborn and a 6-year-old, a 2-year-old and a 12-year-old, etc.) or pairs of the size-variant drawings and asked to state which one of the pair they "would feel most compelled to defend should you see them being beaten." In another experiment they were asked about their feelings to "hug or cuddle" the person depicted. The results of both experiments, summarized in TableB1.1, find a fairly strong reported willingness to defend "newborns" and "2-year olds," and a moderate willingness to defend "older" persons. The reported willingness to cuddle decreased with the "age" of the drawings. Placed in the context of the ethol ogical study of parental caregiving in mammals and birds, Alley bel ieves that his results demonstratea general tendency to protect or cuddle others based on the perception of maturational status.

McCabe (1988) reviews the work of Alley and other similar studies. Taken together, these studies indicate that adults are more likely to protect or nuture individuals with "neotenous" facial features. McCabe defines such features as having a relatively large ratio of cranium size to lower face size. McCabe also cites studies of the facial features of nursery school-aged children under court protection for abuse compared with non-abused age-matched controls. The abused children had smaller ratios of the cranium/lower face-that is, they were less "neotenous" or "cute"- than the non-abused controls.

These psychological experiments and case control studies provide support for the argu- ments developed in this chapter for the evolution of human childhood. In particular, small body size and a superficially infantile appearance promote appropriate parental behavior by older individuals toward children.

\section{LITERATURE CITED}

Aiello LC and Wheeler P (1995) The expensive-tissue hypothesis. Curr. Anthropol. 36:199-221.

Alley TR (1983) Growth-produced changes in body shape and size as determinants of perceived age and adult caregiving. Child Dev. 54:241-248.

Altman J (1980) Baboon Mothers and Infants. Cambridge: Harvard University Press.

Backman G (1934) Das Wachstum der Korperlange des Menchen. KunglickeSvenska Verenskapsakademiens Handlingar 14:145.

Bailey SM, Gershoff SN, McGandy RB, Nondasuta A, Tantiwongse P, Suttapreyasri D, Miller J , and M cCree $P$ (1984) A longitudinal study of growth and maturation in rural Thailand. Hum. Biol. 56:539-557.

Behar M (1977) Protein-caloric deficits in developing countries. Ann. N. Y. Acad. Sci. 300:176-187.

Bekoff $M$ and Beyers J A (1985) The development of behavior from evolutionary and ecological perspectives in mammals and birds. Evol. Biol. 19:215-286.

Bemprad J R (1991) Dementia preacox as a failure of neoteny. Theor. Med. 12:45-53.

Bertalanffy L von (1960) Principles and theory of growth. In WN Nowinski (ed.): Fundamental Aspects of Normal and Malignant Growth. Amsterdam: Elsevier, pp. 137-259.

Blurton-J ones NG (1993) The lives of hunter-gather children: Effects of parental behavior and parental reproductive strategy. In ME Pereira and LA Fairbanks (eds.): J uvenile Primates. Oxford: Oxford University Press, pp. 309-326.

Blurton-J ones NG, Smith LC, O'Connell J F, and Handler J S (1992) Demography of the Hadza, an increasing and high density population of savanna foragers. Am. J. Phys. Anthropol . 89:159-181.

Bock RD, and Thissen DM (1976) Fitting multicomponent models for growth in stature. Proc. Ninth Int. Biometric Conf. 1:431-442.

Bock RD and Thissen D (1980) Statistical problems of fitting individual growth curves. In FE J ohnston, AF Roche, and C Susanne (eds.): Human Physical Growth and Maturation, Methodologies and Factors. New York: Plenum, pp. 265-290.

Bogin B (1988) Patterns of Human Growth. Cambridge: Cambridge University Press.

Bogin B (1990) The evolution of human childhood. BioScience 40:16-25.

Bogin B (1993) Why must I be a teenager at all? New Scientist 137:34-38.

Bogin B (1994a) Adolescence in evolutionary perspective. Acta Paediatr. (Suppl.) 406:29-35.

Bogin B (1994b) The evolution of learning. In T Husen and TN Postlethwaite (eds.): The International Encyclopedia of Education, 2nd ed. Oxford: Pergamon, pp. 2681-2685.

Bogin B (1995) Growth and development: Recent evolutionary and biocultural research. In N Boaz and LD Wolfe (eds.): Biological Anthropology: The State of the Science. Bend, OR: I nternational I nstitute for Human Evolutionary Research, pp. 49-70.

Bogin B (1996) Childhood in evolutionary and biocultural perspective. In CJ K Henry and SJ Ulijaszek 
(eds.): Long Term Consequence of Early Environment. Cambridge: Cambridge University Press, pp. 7-22.

Bogin B (in press) The mid-childhood growth spurt. In SJ Ulijaszek, FE J ohnston, and MA Preece (eds.): The Cambridge Encyclopedia of Human Growth. Cambridge: Cambridge University Press.

Bogin B and Smith BH (1996) Evolution of the human life cycle. Am. J. Hum. Biol. 8:703-716.

Bolk L (1926) Das Problem der Menschwerdung. J ena: Gustav Fischer.

Bonner J T (1965) Size and Cycle. Princeton, NJ : Princeton University Press.

Bowman J E and Lee PC (1995) Growth and threshold weaning weights among captive rhesus macaques. Am. J. Phys. Anthropol. 96:159-175.

Boyd E (1980) BS Savara and J F Schilke (eds.): Origins of the Study of Human Growth. Eugene: University of Oregon Health Sciences Center, Dental School.

Boym C (1994) Cover story: By design. Metropol is 13:38.

Brody S (1945) Bioenergetics and Growth. New York: Reinhold.

Brown S (1995) Through the lens of play. ReVision 17:4-8.

Cabana T, J olicoeur P, and Michaud J (1993) Prenatal and postnatal growth and allometry of stature, head circumference, and brain weight in Québec children. Am. J. Hum. Biol. 5:93-99.

Cameron N, Tanner J M, and Whitehouse RH (1982) A longitudinal analysis of the growth of limb segments in adolescence. Ann. Hum. Biol. 9:211-220.

Coelho AM (1985) Baboon dimorphism: Growth in weight, length, and adiposity from birth to 8 years of age. In ES Watts (ed.): N onhuman Primate M odels for Human Growth. New York: Alan R. Liss, pp. 125-159.

Cutler GB J r, Glenn M, Bush M, Hodgen GD, Graham CE, and Loriaux DL (1978) Adrenarche: A survey of rodents, domestic animals, and primates. Endocrinology 103:2112-2118.

Demirjian A (1978) Dentition. In F Falkner and J M Tanner (eds.): Human Growth 2: Postnatal Growth. New York: Plenum, pp. 413-444.

Dettwyler KA (1995) A time to wean: The hominid blueprint for the natural age of weaning in modern human populations. In P Stuart-Macadam and KA Dettwyller (eds.): Breastfeeding: Biocultural Perspectives. New York: Aldine de Gruyter, pp. 39-73.

Eccles J C (1979) The Understanding of the Brain. New York: McGraw-Hill.

Ellison PT (1990) Human ovarian function and reproductive ecology: N ew hypotheses. Am. Anthropol. 92:933952.

Estioko-Griffin A (1986) Daughters of the forest. Natural History 95:36-43.

Galdikas BM and Wood J W (1990) Birth spacing patterns in humans and apes. Am. J. Phys. Anthropol. 83:185-191.

Godfrey L and Sutherland MR (1996) Paradox of peramorphic paedomorphosis: Heterochrony and human evolution. Am. J. Phys. Anthropol. 99:17-42.

Goldsmith J (1993) Language and learning as properties of our species. Modern Philosophy 90:34-38.

Goodall J (1983) Population dynamics during a 15 year period in one community of free-living chimpanzees in the Gombe National Park, Tanzania. Z. Tierpsychol. 61:1-60.

Gould SJ (1977) Ontogeny and Phylogeny. Cambridge, MA: Belknap.

Gould SJ (1979) Mickey Mouse meets Konrad Lorenz. Natural History 88:30-36.

Gould SJ (1981) The Mismeasure of Man. New York: Norton.

Guthrie H and Picciano MF (1995) Human Nutrition. St. Louis: Mosby.
Harvey PH, Martin RD, and Clutton-Brock TH (1987) Lifehistories in comparative perspective. In BB Smuts, DL Cheney, RM Seyfarth, RW Wrangham, and TT Struhsaker (eds.): Primate Societies. Chicago: University of Chicago Press, pp. 181-196.

Hewlitt BS (1991) Intimate Fathers: The Nature and Context of Aka Pygmy Paternal Care. Ann Arbor, MI: University of Michigan Press.

Howell N (1979) Demography of the Dobe !Kung. New York: Academic.

Huxley J S (1932) Problems of Relative Growth. London: Methuen. Reprinted 1972, New York: Dover.

J aswal S (1983) Age and sequence of permanent tooth emergence among Khasis. Am. J. Phys. Anthropol. 62:177-186.

J olly A (1985) The Evolution of Primate Behavior, 2nd ed. New York: Macmillan.

J ones D (1995) Sexual selection, physical attractiveness, and facial neoteny. Curr. Anthropol. 36:723-748.

Karlberg J (1985) The human growth curve decomposed into three additive and partly superimposed components: The FBP model. In Abstracts. Fourth I nternational Congress of Auxology. London: Taylor and Francis, p. 46.

Katz SH, Hediger ML, Zemel BS, and Parks I S (1985) Adrenal androgens, body fat and advanced skeletal age in puberty: New evidence for the relations of adrenarche and gonadarche in males. Hum. Biol. 57:401-413.

Klein RG (1989) The Human Career: Human Biological and Cultural Origins. Chicago: University of Chicago Press.

Kummer B (1952) Untersuchungen uberdie ontogenetische Entwicklung des menschlichen Schadelbasiswinkels. Z. Morphol. Anthropol. 43:331-360.

La Barre W (1991) Shadow of Childhood: Neoteny and the Biology of Religion. Norman: University of Oklahoma Press.

Laird AK (1967) Evolution of the human growth curve. Growth 31:345-355.

Laitman J T and Heimbuch RC (1982) The basicranium of Plio-Pleistocene hominids as an indicator of their upper respiratory systems. Am. J. Phys. Anthropol. 59:323-343.

Lancaster J B and Lancaster CS (1983) Parental investment: The hominid adaptation. In DJ Ortner (ed.): How Humans Adapt. Washington, DC: Smithsonian Institution Press, pp. 33-65.

Lee PC, Majluf P, and Gordon IJ (1991) Growth, weaning, and maternal investment from a comparative perspective. J . Zool. Soc. Lond. 225:99-114.

Leonard WR and Robertson ML (1992) Nutritional requirements and human evolution: A bioenergetics model. Am. J . Hum. Biol. 4:179-195.

Leonard WR and Robertson ML (1994) Evolutionary perspectives on human nutrition: The influence of brain and body size on diet and metabolism. Am. J . Hum. Biol. 6:77-88.

Lieberman P, Crelin ES, and Klatt DH (1972) Phonetic ability and related anatomy of the newborn and adult human, Neanderthal man, and the chimpanzee. Am. Anthropol. 74:287-307.

Lorenz K (1971) Part and parcel in animal and human societies: A methodological discussion. In R Martin (ed. and trans.): Studies in Animal and Human Behavior, vol. 2. Cambridge, MA: Harvard University Press, pp. 115-95.

Lovejoy CO (1981) The origin of man. Science 211:341350.

Marshall WA (1978) Puberty. In F Falkner and J M Tanner (eds.) Human Growth, vol. 2. Postnatal Growth. New York: Plenum, pp. 141-181. 
Martin DE, Swenson RB, and Colins DC (1977) Correlation of serum testosterone levels with age in male chimpanzees. Steroids 29:471-481.

Martin RD (1983) Human Brain Evolution in an E cological Context. Fifty-second J ames Arthur Lecture. New York: American Museum of Natural History.

Mascie-Taylor CGN and Bogin B (eds.) (1995) Human Variability and Plasticity. Cambridge: Cambridge University Press.

McCabe V (1988) Facial proportions, perceived age, and caregiving. In TR Alley (ed.): Social and Applied Aspects of Perceiving Faces. Hillsdale: NJ : Lawerence Earlbaum Associates, pp. 89-95.

McKinney ML and McNamara KJ (1991) Heterochrony: The Evolution of Ontogeny. New York: Plenum.

Montagu A (1989) Growing Young, 2nd ed. Massachusetts: Bergin and Garvey.

Nishida T, Takasaki H, and Takahata Y (1990) Demography and reproductive profiles. In T Nishida (ed.): The Chimpanzees of the Mahale Mountains: Sexual and Life History Strategies. Tokyo: University of Tokyo Press, pp. 63-97.

Parker LN (1991) Adrenarche. Endocrinol. Metab. Clin. North Am. 20:71-83.

Parker ST (1996) Using cladistic analysis of comparative data to reconstruct the evolution of cognitive development in hominids. In E Martins (ed.): Phylogenies and the Comparative Method in Animal Behavior. Oxford: Oxford University Press, pp. 433-448.

Pereira ME, and Altmann J (1985) Development of social behavior in free-living nonhuman primates. In ES Watts (ed.): Nonhuman Primate Models for $\mathrm{Hu}$ man Growth and Development. New York: Alan R. Liss, pp. 217-309.

Pereira ME and Fairbanks LA (eds.) (1993) J uvenile Primates. Oxford: Oxford University Press.

Piaget J (1954) The Construction of Reality in the Child. New York: Basic Books.

Piaget J and Inhelder B (1969) The Psychology of the Child. New York: Basic Books.

Prader A (1984) Biomedical and endocrinological aspects of normal growth and development. In J Borms, R Hauspie, A Sand, C Susanne, and M Hebbelinck (eds.): Human Growth and Development. New York: Plenum, pp. 1-22.

Rogoff B, Seller MJ, Pirrotta S, Fox N, and White SH (1975) Age assignment of roles and responsibilities of children: A cross cultural survey. Hum. Dev. 18:353369.

Scammon RE (1930) The measurement of the body in childhood. In J A Harris, CM J ackson, DG Paterson, and RE Scammon (eds.): The Measurement of Man. Minneapolis: University of Minnesota Press, pp. 173215.

Schultz AH (1960) Age changes in primates and their modification in man. In JM Tanner (ed.): Human Growth. Oxford: Pergamon, pp. 1-20.

Shea BT (1989) Heterochrony in human evolution: The case for neoteny reconsidered. Yrbk Phys. Anthropol. 32:69-101.

Short RV (1976) The evolution of human reproduction. Proc. R. Soc. Lond. [B] 195:3-24.

Simons EL (1989) Human origins. Science 245:13431350.

Smail PJ, Faiman C, Hobson WC, Fuller GB, and Winter J S (1982) Further studies on adrenarche in nonhuman primates. Endocrinology 111:844-848.

Smith BH (1991a) Age at weaning approximates age of emergence of the first permanent molar in non-human primates. Am. J. Phys. Anthropol. Suppl. 12:163-164 (abstract)

Smith BH (1991b) Dental development and the evolution of life history in Hominidae. Am. J . Phys. Anthropol. 86:157-174.
Smith BH (1992) Life history and the evolution of human maturation. Evol. Anthropol. 1:134-142.

Smith BH, Crummett TL, and Brandt KL (1994) Ages of eruption of primate teeth: A compendium for aging individuals and comparing life histories. Yrbk Phys. Anthropol. 37:177-231.

Spencer H (1886) The Principles of Biology, vols. 1 and 2. New York: D. Appleton.

Starck D and Kummer B (1962) Zur Ontogenese des Schimpansenschadels. Anthropol. Anz. 25:204-215.

Stearns SC (1992) The Evolution of Life Histories. Oxford: Oxford University Press.

Tanner J M (1947) The morphological level of personality. Proc. R. Soc. Med. 40:301-303.

Tanner J M (1962) Growth at Adolescence, 2nd ed. Oxford: Blackwell Scientific.

Tanner J M, Wilson ME, and Rudman CG (1990) Pubertal growth spurt in the female Rhesus monkey: Relation to menarche and skeletal maturation. Am. J. Hum. Biol. 2:101-106

Teleki GE, Hunt E, and Pfifferling J H (1976) Demographic observations (1963-1973) on the chimpanzees of the Gombe National Park, Tanzania. J . Hum. Evol. 5:559-598.

Todd J T, Mark LS, Shaw RE, and Pittenger J B (1980) The perception of human growth. Sci. Am. 242(2):132144.

Ulijaszek SJ and Strickland SS (1993) Nutritional Anthropol ogy: Prospects and Perspectives. London: Smith Gordon.

Vrba ES (1996) Climate, heterochrony, and human evolution. J . Anthropol. Res. 52:1-28.

Watts DP and Pusey AE (1993) Behavior of juvenile and adolescent great apes. In ME Pereira, LA Fairbanks (eds.): J uvenile Primates. Oxford: Oxford University Press, pp. 148-170.

Watts ES and Gavan J A (1982) Postnatal growth of nonhuman primates: The problem of the adolescent spurt. Hum. Biol. 54:53-70

Weirman ME and Crowley WF J r (1986) Neuroendocrine control of the onset of puberty. In F Falkner and J M Tanner (eds.): Human Growth, 2nd ed., vol. 2. New York: Plenum, pp. 225-241.

Weisner TS (1987) Socialization for parenthood in sibling caretaking societies. In J B Lancaster, J Altmann, AS Rossi, and LR Sherrod (eds.): Parenting Across the Life Span: Biosocial Dimensions. New York: Aldine de Gruyter, pp. 237-270.

Weisner TS (1996) The 5-7 transition as an ecocultural project. In A Samaroff and M Haith (eds.): Reason and Responsibility: The Passage Through Childhood. Chicago: University of Chicago Press, pp. 295-326.

Weisner TS and Gallimore R (1977) My brother's keeper: Child and sibling caretaking. Curr. Anthropol. 18:169190.

White SH (1965) Evidence for a hierarchical arrangement of learning processes. In LP Lipsitt and CC Spiker (eds.): Adv. Child Dev. Behav., vol. 2. New York: Academic, pp. 187-220.

Whiting B and Edwards C (1988) Children of Different Worlds. The Formation of Social Behavior. Cambridge, MA: Harvard University Press.

Whiting $B$ and Whiting J WM (1975) Children of Six Cultures. A Psycho-cultural Analysis. Cambridge, MA: Harvard University Press.

Winter J SD (1978) Prepubertal and pubertal endocrinology. In F Falkner and J M Tanner (eds.): Human Growth, vol. 2, Postnatal Growth. New York: Plenum, pp. 183-213.

Worthman CM (1986) Later-maturing populations and control of the onset of puberty (abstract). Am. J . Phys. Anthropol. 69:282. 